\title{
Temporal Variability of Climatic Parameters of Yamuna River Basin: Spatial Analysis of Persistence, Trend and Periodicity
}

\author{
R. K. Rai ${ }^{1, *}$, Alka Upadhyay ${ }^{1}$ and C. S. P. Ojha ${ }^{2}$ \\ ${ }^{1}$ DHI (India) Water \& Environment Pvt Ltd, III ${ }^{\text {rd }}$ Floor, NSIC-STP Complex, NSCI Bhawan, New Delhi-110 020, India \\ ${ }^{2}$ Department of Civil Engineering, Indian Institute of Technology Roorkee, Roorkee-247 667, Uttarakhand, India
}

\begin{abstract}
Identification of the precise nature and attributes of the time series of climatological data is very important and is usually the first step for water resources planning and management. Such exercise is very important for hydro-climatic extremes. In many instances, a climatic time series is generally not statistically independent but is comprised of patterns of persistence, cycles, trends or some other non-random components. To see the importance of the subject, this paper describes the statistical approach used to investigate the presence and extent of persistence, trend and periodicity in climatic time series. The methodology was applied to investigate the spatial distribution pattern of the indicative hydro-climatic variables over the Yamuna River basin of India. Hydro-climatic time series used in the analysis were annual rainfall; Monsoon and Non-monsoon rainfall; annual, Monsoon and Non-monsoon rainydays; onset of effective monsoon; and aridity index.
\end{abstract}

Keywords: Climate, time series, persistence, trend, periodicity, Yamuna river basin, India.

\section{INTRODUCTION}

Climate is the most important driving parameter that causes year-to-year variability in socio-economic and environmental systems including the availability of water resources. It affects the development and planning of water resources schemes such as flood prevention and control, drought management, food and fiber production, etc. Further, any change in climate will increase the uncertainty in water resources planning. Apart from this, changes in climatic pattern will have profound effects and consequences for natural and agricultural ecosystems and for society as whole. These changes could even alter the location of the major crop production regions on the earth [1]. The shifting from 'normal weather', with its associated extreme events will surely change the zones of crop adaptation and cultural practices required for successful crop production. Climate and weather induced instability in food and fibre supplies will alter social and economic stability and regional competitiveness [1]. Therefore, the analysis of hydro-climatic variables such as rainfall, potential evapotranspiration, etc becomes a prerequisite task to understand the climatic changes.

In recent years, there has been a considerable concern about the possibility of climatic changes. Alteration in our climate is governed by a complex system of atmospheric and oceanic processes and their interactions. Atmospheric processes also result in increase in surface-level ultraviolet radiation and changes in temperature and rainfall pattern. Human activities on the other hand are responsible for changes in ecosystem due to increased emissions rate of $\mathrm{CO}_{2}$ and other

*Address correspondence to this author at the DHI (India) Water \& Environment Pvt Ltd, III ${ }^{\text {rd }}$ Floor, NSIC-STP Complex, NSCI Bhawan, New Delhi-110 020, India; Tel: +91-9711295648; Fax: +91-11-47034501;

E-mail: rai.raveendra@gmail.com green house gases. The evidence using state-of-art computer models incorporating as much of the theoretical understanding of the earth's weather suggests that global warming is occurring along with shifting patterns of rainfall and incidents of extreme weather events [2]. It was demonstrated that global surface warming has been taking place at the rate of $0.74 \pm 0.18{ }^{\circ} \mathrm{C}$ over the period of 1906-2005 [2] and it was expected more in the next century than what has occurred during the past 10,000 years [3]. The increased atmospheric moisture content associated with warming might be expected to increase the global mean precipitation. Global annual land mean precipitation showed a small, but uncertain, upward trend of approximately $1.1 \mathrm{~mm}$ per decade (uncertainty $\pm 1.5 \mathrm{~mm}$ ) over 1901-2005. During the 20th century, precipitation has generally increased from latitudes $30^{\circ}$ to $85^{\circ} \mathrm{N}$ over land; but notable decreases have occurred between latitudes $10^{\circ} \mathrm{S}$ and $30^{\circ} \mathrm{N}$ in the last $30-40$ years. In western Africa and southern Asia the linear trends in rainfall decrease during 1900-2005 were $7.5 \%$ per century (significant statistically at $<1 \%$ level), whereas over much of northwest India shows increase in the rainfall with more than $20 \%$ per century [2]. At lower latitudes, especially seasonally dry and tropical regions, crop productivity is projected to decrease for even small local temperature increases $\left(1-2{ }^{\circ} \mathrm{C}\right)$, which would increase the food risk [3]. Based on the data for the period of 1901-2005, it was demonstrated that all-India mean annual temperature had been rising at $0.05{ }^{\circ} \mathrm{C} /$ decade, with maximum temperature at $+0.07{ }^{\circ} \mathrm{C} / \mathrm{dec}$ ade and minimum temperature at $+0.02{ }^{\circ} \mathrm{C} /$ decade [4]. As a result, the diurnal temperature range shows an increase of 0.05 ${ }^{\circ} \mathrm{C} /$ decade. However, in northern India, the average temperature is falling at the rate of $-0.38{ }^{\circ} \mathrm{C}$ unlikely to rise in allIndia average temperature (i.e at $+0.42{ }^{\circ} \mathrm{C} /$ Century) [5].

Change in the precipitation pattern is also reported for the 21 st century. Kripalani et al. [6] reported an increasing trend 
in South-Asian mean monsoon precipitation associated with intensification of land-ocean pressure gradient during the establishment phase of the monsoon. At a regional scale, diversified precipitation pattern were investigated by various scientists / agencies. A declining trend in precipitation was observed over Greece [7], Canadian Prairies [8], Bologna in Italy [9]; whereas North Carolina [10], Mainland Spain [11] experienced rising trend. There was no trend identified in precipitation over the Iberian Peninsula [12] and Japan [13]. Beside these, a comprehensive review of precipitation changes was also carried out at global and regional level, and a decreasing precipitation trends was identified in Russia, Kazakhstan, China and Thailand with global increase in variance [14]. Probable causes of change in rainfall may be due to: (a) global climate shift [15] or weakening global monsoon circulation [16-18]; (b) reduction in forest cover [19-28] and change in land use including introduction of irrigated agriculture [29-32]; and (c) increasing aerosol due to anthropogenic activities [33-36].

In India, a diversified climate with large variations in the rainfall is experienced. Rainfall variability of the Indian monsoons has been extensively studied by several investigators [37-39]. An extensive review of studies of rainfall pattern of India excluding the Himalayan region was well presented by Basistha et al. [40]. Based on these studies, a consensus regarding evidence of insignificant trend in annual rainfall series can be reported, though divergences do exist depicting an increasing [41] or decreasing trend [42]. Regional analyses of the data revealed increasing rainfall trends over the Indus, Ganga, Brahmaputra, Krishna and Cauvery basins [42], the west coast [43], north Andhra Pradesh and northwest India [44], Rohtak and Kurukshetra of Haryana [45], Delhi [46], west Madhya Pradesh [47], coastal Orissa [48] and peripheries of the Rajasthan desert [49], but decreasing trends in the central Indian basins of Sabarmati, Mahi, Narmada, Tapi, Godavari and Mahanadi [42], east Madhya Pradesh and adjoining areas, northeast India [50] and parts of Gujarat [44], south Kerala [51,52] and central north Indian divisions [53]. Singh et al. [54] have indicated increasing trend of annual rainfall and relative humidity in north Indian River basins, though the least variation was observed in monsoon rainfall. Studies by Kothyari and Singh [55] and Kothyari et al. [21] reported decreasing rainfall trend over the Ganga basin, beginning around the second half of the 1960s. This was elaborated by Singh and Sontakke [56] to be increasing over western Indo-Gangetic Plains and decreasing (statistically insignificant, though) over the central part. IINC [57] depicts a decreasing summer monsoon rainfall trend over the state of Uttarakhand. Basistha et al. [40] attempted to explore changes in rainfall pattern in the Indian Himalayas during the 20th century and revealed that the most probable year of change in annual as well as monsoon rainfall in the region was 1964. There was an increasing trend up to 1964 (corroborating with all India and nearby plains), followed by a decreasing trend in 1965-1980 (exclusive to this region). In the entire region, changes are most conspicuous over the Shivaliks and the southern part of the Lesser Himalayas. Chase et al. [58] indicated a consistent reduction in intensity of all tropical monsoon systems since 1950. A decrease in monsoon precipitation in the central Himalayas (Tibet, China) was identified from early 1920s to the present [17]. However, a substantial global climate shift has been reported in the late 1960s affecting South AmericaAfrica [59]. Apart from the rainfall pattern, other meteorological parameters show significant variations. Jhajharia et al. [60] analyzed the temporal characteristics of pan evaporation (Epan) under the humid conditions for northeast India and reported general decreasing trends in pre- and monsoon seasons. A declining trend in sunshine hours and wind speed, and increasing trend in relative humidity was also reported for most of the stations. Bandyopadhyay et al. [61] reported similar results for India in case of reference evapotranspiration (ETo) for the period of 1971-2002, which was mainly caused by a significant increase in relative humidity and a consistent significant decrease in the wind speed throughout the country. However, a general increase in rainfall was not found in recent years.

Looking into the aforesaid facts and studies, it can be stated that there is no consensus among the studies. Possibly, it may be due to analysis of climatic variable at regional scale, which induces loss of spatial information of the variable. Therefore, for water resources planning, it seems to be logical and compulsory to analyze the hydro-climatic variables at small scale that it can be rationalized at river basin scale. Though, the change in climate is governed by the complex system of atmosphere and oceanic processes and their interaction, but due to limitation on availability of wide variety of atmospheric data, this study focus on the analysis of indicative hydro-climatic parameters to demonstrate the climate change or changes in weather patterns.

In the present study, the Yamuna River basin was investigated to demonstrate the climatic fluctuation/variability which exhibit high spatio-temporal variability in terms of climate (semi-arid to humid subtropical climates) and topography. Parameters that directly influence the water resources and agricultural planning (viz., annual, monsoon and nonmonsoon rainfall; number of annual, monsoon and nonmonsoon rainydays; onset of effective monsoon; and aridity index) were considered.

\section{STATISTICAL TEST FOR CLIMATOLOGICAL DATA}

To define the climatic fluctuations exhibited in the hydro-climatic time series is an important aspect of the analysis. From a statistical point of view, the study of climatic fluctuations is a problem of time series analysis. Statistical evidence of persistence in such time series is equated with evidence of bona fide climatic fluctuations and said to be dependent. In many instances, a time series is generally not statistically independent but is comprised of persistence, cycles, trends or other non-random components. A steady and regular movement in a time series through which the values are on average either increasing or decreasing is termed a trend. This type of behavior can be local, in which case the nature of the trend is subject to change over short intervals of time, or, on the other hand, it can be visualize a global trend that is long lasting. If a trend in a hydrologic time series appear it is, in effect, part of a low frequency oscillatory movement induced by climatic factors or through change in land use and catchment characteristics. Looking into the importance of the deterministic components of climatic series, in the present study, the statistical test for persistence, trend and periodicity was discussed, and analyzed for the hydro-climatic variables of Yamuna River basin. 


\section{Persistence}

For climatic variability and changes, definition of persistence given by WMO [62] is very common. According to this definition, persistence is a "tendency for successive values of the series to "remember" their antecedent values, and to be influenced by them.' The value of $r_{l}$ has been used to detect the possible persistence in the observed year-to-year variations of normalized anomaly series and to examine its nature and magnitude. The approach proposed by WMO [62] and Matalas [63] was widely used later in many studies related to long-term climatic variations [64-72]. To test the persistence in the climatological time series normalized anomaly of the time series is used, which is obtained as follows:

$X_{t}=\left(x_{t}-\bar{x}\right) / \sigma$

where, $X_{t}$ is the normalized anomaly of the series, $x_{t}$ is the observed time series, $\bar{x}$ and $\sigma$ are the long-term mean and standard deviation of annual/seasonal time series. All serial correlation coefficients of normalized climatic series are computed for lags $L=0$ to $m$, where $m$ is the maximum lag (i.e. $m=n / 3) ; n$ is the length of the series. The serial correlation coefficient was computed from eq. (2).

$$
r_{L}=\frac{\sum_{t=1}^{n-L}\left(X_{t}-\bar{X}_{t}\right) \cdot\left(X_{t+L}-\bar{X}_{t+L}\right)}{\left[\sum_{t=1}^{n-L}\left(X_{t}-\bar{X}_{t}\right)^{2} \cdot \sum_{t=1}^{n-L}\left(X_{t+L}-\bar{X}_{t+L}\right)^{2}\right]^{1 / 2}}
$$

where, $r_{L}$ is the lag- $L$ serial correlation coefficient of the series. To test the significance of serial correlation, eq. (3) is used [73].

$\left(r_{L}\right)_{t_{g}}=\frac{-1 \pm t_{g}(n-L-1)^{1 / 2}}{n-L}$

where, $\left(r_{L}\right)_{t_{g}}$ is the normally distributed value of $r_{L}, t_{g}$ is the normally distributed statistic at $g$ level of significance. The value of $t_{g}$ are $1.645,1.965$ and 2.326 at significance level of $0.10,0.05$ and 0.01 , respectively.

The hypothesis test was carried out at 0.05 level as this level is sufficient for engineering point of view. The 'null' hypothesis of the randomness of climatic series against the serial correlation is rejected for the large value of $r_{1}$. If $r_{1}$ of the series is not statistically significant or is significant but has a negative sign, it is assumed that the series does not contain the persistence and the appropriate null continuum is termed as 'white noise'. On the other hand, the persistence in the time series is characterized by a positive serial correlation. In this case, a "Markov red noise" type 'null' continuum is ensured using the $r_{2}$ and $r_{3}$ [62]. In addition to this significant negative $r_{l}$ are very likely to be indicative of high-frequency oscillations, whereas significant positive $r_{l}$ is likely to be indicative of low-frequency fluctuations and persistence in climatic series. Therefore, in the study serial correlation coefficients up to lag-3 were assessed.

\section{Trend}

There are several approaches for detecting the trend in the time series. These approaches can be either parametric or non-parametric. Parametric methods assumed the data should normally distributed and free from outliers. On the other hand, non-parametric methods are free from such assumptions. The most popularly used non-parametric tests for detecting trend in the time series is the Mann-Kendall (MK) test $[74,75]$. It is widely used for different climatic variables [76-78,8,79-87,40].

For original Mann-Kendall test, the time series must be serially independent in nature. However, in many real situations, the observed data are serially dependent (i.e., autocorrelated). The autocorrelation in the observed data will results in misinterpretation of trend test results. Cox and Stuart [88] stated that "positive serial correlation among the observations would increase the chance of significant answer, even in the absence of a trend". A closely related problem that has been studied is the case where seasonality exists in the data [76]. By dividing the observations into separate classes according to the season and then performing the Mann-Kendall trend test on the sum of the statistics from each season, the effect of seasonality can be eliminated. This modification is called the seasonal Mann-Kendall test [76,77]. Although the seasonal test eliminates the effect of seasonal dependence, it does not account for the correlation in the series within the season [77]. The same problem exists when yearly time series is considered for the analysis as it significantly autocorrelated. Therefore, in this paper, the original Mann-Kendall test is described along with its modified versions that accounts for the serially dependence in the data.

\section{Mann-Kendall Test [74,75]}

The Mann-Kendal (MK) test searches for a trend in a time series without specifying whether the trend is linear or nonlinear [89]. The Mann-Kendall test for detecting monotonic trends in hydrologic time series is described by Yue et al. [82]. It is based on the test statistics S, which is defined as:

$$
S=\sum_{i=1}^{n-1} \sum_{j=i+1}^{n} \operatorname{sgn}\left(x_{j}-x_{i}\right)
$$

where, $x_{j}$ are the sequential data values, $n$ is the length of the data set and

$\operatorname{sgn}(t)= \begin{cases}1, & \text { for } t>0 \\ 0, & \text { for } t=0 \\ -1, & \text { for } t<0\end{cases}$

The value of $\mathrm{S}$ indicates the direction of trend. A negative (positive) value indicate falling (rising) trend. MannKendall have documented that when $n \geq 8$, the test statistics $\mathrm{S}$ is approximately normally distributed with mean and variance as follows:

$$
\begin{aligned}
& E(S)=0 \\
& \operatorname{Var}(S)=\frac{1}{18}\left[n(n-1)(2 n+5)-\sum_{i=1}^{m} t_{i}\left(t_{i}-1\right)\left(2 t_{i}+5\right)\right]
\end{aligned}
$$


where, $\mathrm{m}$ is the number of tied groups and $t_{i}$ is the size of the $i^{\text {th }}$ tie group. The standardized test statistics $\mathrm{Z}$ is computed as follows.

$$
Z_{M K}= \begin{cases}\frac{S-1}{\sqrt{\operatorname{Var}(S)},} & \text { for } S>0 \\ 0 & \text { for } S=0 \\ \frac{S+1}{\sqrt{\operatorname{Var}(S)},}, & \text { for } S<0\end{cases}
$$

The standardized Mann-Kendall statistics $\mathrm{Z}$ follows the standard normal distribution with zero mean and unit vari-

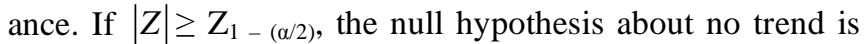
rejected at the significance level $\alpha$ (10\% in this study).

\section{Modified Mann-Kendall Test}

For Modified Mann-Kendall's test, the statistics $S$ tends to normality for large $n$, with mean and variance given by:

$E(S)=0$

$\operatorname{Var}(S)=n(n-1)(2 n+5) / 18$

The statistics $S$ is given by eq. (8):

$S=a_{i j}=\sum_{i=1}^{n-1} \sum_{j=i+1}^{n} \operatorname{sgn}\left(x_{j}-x_{i}\right)$

With the same mean and variance as in eqs. (9) and (10), a modified version of the Mann-Kendall test which is robust in the presence of autocorrelation is proposed based on the modified variance of $S$ given by eq. (12).

$V^{*}(S)=\operatorname{Var}(S) \cdot \frac{n}{n_{s}^{*}}=\frac{n(n-1)(2 n+5)}{18} \cdot \frac{n}{n_{s}^{*}}$

where, $n / n_{s}^{*}$ represents a correlation due to the autocorrelation in the data. The $n / n_{s}^{*}$ is evaluated using eq. (13).

$\frac{n}{n_{s}^{*}}=1+\frac{2}{n(n-1)(n-2)} \times \sum_{i=1}^{n-1}(n-i)(n-i-1)(n-i-2) \rho_{s}(i)$

In eq. (13), $\mathrm{n}$ is the actual number of the observations and $\rho_{s}(i)$ is the autocorrelation function of the ranks of the observations. The advantage of using eq. (12) and (13) for the evaluation of variance of $S$ is that there is no need of either normalized data or their autocorrelation function. The autocorrelation of ranks of observations $\rho_{s}(i)$ is related with the parent autocorrelation function and is given as follows [75]:

$\rho(i)=2 \sin \left(\frac{\pi}{6} \rho_{s}(i)\right)$

Inverse of eq. (14) can therefore be used to evaluate the autocorrelation of rank $\rho_{s}(i)$ that appeared in eq. (13) and is given by eq. (15). $\rho_{s}(i)=\frac{6}{\pi} \sin ^{-1}\left(\frac{\rho(i)}{2}\right)$

The significance of the trends is tested by comparing the standardized test statistics Z.

$$
Z=\frac{S}{\left[V^{*}(S)\right]^{0.5}}
$$

A significant level of $\alpha=0.1$ for the autocorrelation of the ranks $\rho_{s}(i)$ was used, which produce the best overall empirical significance level. The serial correlation of the ranks of the series and their significance test can be computed from eqs. (2) and (3).

\section{Mann-Kendall Test with Pre-Whitening}

An alternate approach to perform the trend analysis of time series with presence of serial correlation using the Mann-Kendall test is to remove the serial correlation from data first and then apply the test. Several approaches have been suggested for removing the serial correlation from a data set prior to applying the test. The pre-whitening approach is most common which involves computation of serial correlation and removing the correlation if the calculated serial correlation is significant at 0.05 significance level [81]. The pre-whitening is accomplished as follows:

$X_{t}^{\prime}=x_{t+1}-r_{1} \times x_{t}$

where, $x_{t}=$ original time series with autocorrelation for time interval $t ; X_{t}^{\prime}=$ pre-whitened time series; and $r_{1}=$ the lag-1 autocorrelation coefficient. This pre-whitened series is then subjected to Mann-Kendall test (i.e. eqs. 4 to 8) for detecting the trend.

\section{Periodicity}

Periodicity is one of the deterministic components in the time-series. Most of the climatic, atmospheric and hydrological time-series would consist of a combination of stochastic and deterministic components. The power spectrum is a method of analysis that was developed to handle the problem of periodicity in variations of natural events observed in time, such as in climatological and hydrological time series. Power spectrum analysis, also called generalized harmonic analysis, was derived from the principles first developed by Wiener $[90,91]$. It is based on the premise that the time series are not necessarily composed of a finite number of oscillations, each with a discrete wavelength, but rather that they consist of virtually infinite number of small oscillations spanning a continuous distribution of wavelengths. The spectrum therefore, gives the distribution of variations in a time series over a continuous domain of all possible wavelengths.

Procedures for computing the power spectra may vary. Here, in this study, an approach described in WMO [62], developed by Tukey [92] and Blackman and Tukey [93] was employed. A detailed description of this approach can also be found in various textbooks [93-95]. It can be summarized through the following steps: 
(i) First, all serial correlation coefficients of normalized climatic series (eq. 1) are computed for lags from $L=0$ to $m$, where $m$ is the maximum lag $(m=n / 3)$. The serial correlation coefficient can be computed using eq. (2).

(ii) Using the values of $r_{L}$, the 'raw' spectral estimates, $\hat{s}_{k}$ are computed using the following set of equations:

$\hat{s}_{0}=\frac{1}{2 m}\left(r_{0}+r_{m}\right)+\frac{1}{m} \sum_{L=1}^{m-1} r_{L}$

$\hat{s}_{k}=\frac{r_{0}}{m}+\frac{2}{m} \sum_{L=1}^{m-1} r_{L} \operatorname{Cos}\left(\frac{\pi k L}{m}\right)+\frac{1}{m} r_{m}(-1)^{k}$;

for $k=1,2, \ldots \ldots ., m-1$

$$
\hat{s}_{m}=\frac{1}{2 m}\left[r_{0}+(-1)^{m} r_{m}\right]+\frac{1}{m} \sum_{L=1}^{m-1}(-1)^{L} r_{L}
$$

Smallest is the value of $k$ longest will be the wavelength of the spectrum, i.e. shortest wavelength is achieved at $k=$ $m$.

(iii) The raw spectrum $\hat{s}_{k}$ is then smoothened with a 3term weighted average. For smoothing, procedure suggested by Hanning was used [62].

$s_{0}=\left(\hat{s}_{0}+\hat{s}_{1}\right) / 2$

$s_{k}=\left(\hat{s}_{k-1}+2 \hat{s}_{k}+\hat{s}_{k+1}\right) / 4$; for $k=1,2, \ldots \ldots ., m-1$

$s_{m}=\left(\hat{s}_{m-1}+\hat{s}_{m}\right) / 4$

The averaging procedure is performed to derive a constant estimate of the final spectrum in terms of $m+1$ discrete estimates [62].

\section{Statistical Significance Test}

The procedure for evaluating the results of power spectrum analysis mention in WMO [62] is described below:

(i) A 'null' hypothesis continuum is fitted to the computed spectrum. To start with, significance of the lag-1 serial correlation coefficient $r_{1}$ of the climatic series is tested at 90 percent confidence level. The 'null' hypothesis of the randomness of climatic series against the serial correlation is rejected for the large value of $\left(r_{1}\right)_{t}$. If $r_{1}$ is not significantly differ from zero, then series is regarded to be free from persistence. In this case, the appropriate null continuum is 'white noise'. In other words, a horizontal straight line, the value of which is everywhere equal to the average of the values of all the $m+1$ 'raw' spectral estimates (i.e., $\bar{s}$ ) in the computed spectrum (i.e., $S_{k}=\bar{s}$ ), is taken as the most suitable theoretical approach.

(ii) If the computed $r_{1}$ is positive and statistically significant, serial correlation coefficients for lag-2 and lag-3 are checked to see whether they approximate the exponential relations $r_{2} \cong r_{1}^{2}$ and $r_{3} \cong r_{1}^{3}$ [62]. If these relations are ensured with the computed serial coefficients, the approximate 'null' continuum is assumed as the simple "Markov red noise", whose shape depends on unknown value of the lag-1 serial correlation coefficient for a population $\rho$. Then the 'null' continuum can be created by following approximate procedure. By assuming that the sample $r_{1}$ is an unbiased estimation of $\rho$, various chose of the Harmonic number of $k$ between $k=0$ to $m$ are assessed:

$S_{k}=\bar{s}\left(\frac{1-r_{1}^{2}}{1+r_{1}^{2}-2 r_{1} \operatorname{Cos}\left(\frac{\pi k}{m}\right)}\right)$

where, $\bar{s}$ is the average of all $m+1$ 'raw' spectral estimates $\hat{s}_{k}$ in the computed spectrum. The resulting values of $S_{k}$ can be plotted superposed on the sample spectrum, and a smoothed curve passed through these values to reach the required null continuum.

(iii) If $r_{1}$ is statistically significant but a few serial correlation coefficient for higher lags do not show the required exponential relations (i.e., $r_{2} \cong r_{1}^{2}$ and $r_{3} \cong r_{1}^{3}$ ) with $r_{1}$, then doubt arises as to whether the simple Markov-type persistence is the dominant form of non-randomness in series of climatic observations. Nevertheless, WMO [62] suggested that this procedure could be continued with just as before to compute the red noise continuum for $r_{1}$.

(iv) At this stage of the power spectrum analysis a first choice of the null continuum is made, and this selected continuum is superposed on the studied spectrum. In this case, it would be possible to make an assessment of the spectrum for its consistency with the chosen continuum. Then, the value of each spectral estimate $s_{k}$ is compared with the local value of the null continuum.

The statistic associated with the each spectral estimate is the ratio of the magnitude of the spectral estimate to the local magnitude of the continuum (red noise continuum). Tukey [92] found that the quantity of this ratio is distributed as Chisquare divided by the degree of freedom. The degree of freedom, $v$, of each estimate of a computed spectrum is given as follows.

$v=(2 n-m / 2) / m$

The ratio of any sample spectral estimate $s_{k}$ to its local value of the red noise continuum is then compared with critical percentage-point levels of $\chi^{2} / v$ distribution for the proper $v$ value. This comparison produces the required statistical significance level. The $\chi^{2}$ value can be obtained from standard statistical books.

(v) In a sample spectrum, critical percentage-point levels of the $\chi^{2} / v$ distribution, e.g. the 0.95 confidence level, is the same for all spectral estimates $s_{k}$. The confidence limits are finally derived by multiplying the 'null' continuum (i.e. $\left.S_{k}\right)$ with the $\chi^{2} / v$.

(vi) Finally, the cycle associated in the time series is computed as follows. 
$P=2 m / L$

\section{APPLICATION}

The test described for the persistence, trend and periodicity was applied on the hydro-climatic data of Yamuna River basin. The River Yamuna is the largest tributary of River Ganga (Fig. 1). This river is as prominent and sacred as the great River Ganga itself. The total length of the Yamuna River from its origin at Saptrishi Kund to its confluence with Ganga at Allahabad is $1376 \mathrm{~km}$ traversing through five states. The main stream of the river originates from the Yamunotri glacier (Saptrishi Kund) near Bander punch peaks $\left(38^{\circ} 59^{\prime} \mathrm{N} 78^{\circ} 27^{\prime} \mathrm{E}\right)$ in the Mussoorie range of the lower Himalayas at an elevation of about 6320 meter above mean sea level in Uttarkashi district of Uttarakhand. The head waters of the Yamuna river are formed by several melt streams, the chief of them gushing out of the morainic smooth at an altitude of $3250 \mathrm{~m}, 8 \mathrm{~km}$ North West of the Yamunotri hot springs at latitude $31^{\circ} 02^{\prime} 12^{\prime \prime} \mathrm{N}$ and longitude $78^{\circ} 26^{\prime} 10^{\prime \prime}$. In the upper reaches, the Rishi Ganga (right bank), and Unta and Hanuman Ganga (left bank) join the Yamuna River. In the lower Himalayan ranges the Yamuna River receives water from Kamal, Tons, Giri and Bata on its right bank and on its left bank receives the Aglag and Asan river tributaries. The Chambal, Betwa, Sind and Ken are the important tributaries joining the Yamuna on the right bank in the plain, and the Hindon River on the left bank. Among all these tributaries, Tons at the hills and Chambal at the plains are the most important tributaries in terms of their discharges. The Tons is the principal source of water in the mountainous range and generally carries more water than the mainstream. In the plains, during the non-monsoon period, the River Chambal contributes about 5-10 times more water to the Yamuna than its own flow. However, since 2003, there is a significant reduction in the discharge of the Chambal River. In the basin, most of the rainfall occurs during the monsoon. The im- pact of this rainfall pattern mostly influences flooding. During the non-monsoon period the river flow is reduced significantly and some rivers stretches become dry. The Yamuna River carries almost $80 \%$ of the total annual flow during the monsoon period.

The Yamuna basin (Fig. 1) is comprised of a total drainage area of $345848 \mathrm{~km}^{2}$ extended between the latitudes of $22^{\circ} 24^{\prime} 22.3^{\prime \prime}$ to $31^{\circ} 30^{\prime} 56.6^{\prime \prime}$ and longitudes of $73^{\circ} 17^{\prime} 37.26^{\prime \prime}$ to $81^{\circ} 57^{\prime} 42.16^{\prime \prime}$. Based on the topography (i.e. elevation), the Yamuna basin can be divided into three regions, i.e. the hilly region with drainage area of $11700 \mathrm{~km}^{2}$ (> $600 \mathrm{~m}$ above $\mathrm{msl})$, the foot hills and Plateau region having drainage area of $172917 \mathrm{~km}^{2}$ (300-600 $\mathrm{m}$ above $\mathrm{msl}$ ), and plains and valleys with drainage area of $161231 \mathrm{~km}^{2}$ (100-300 m above $\mathrm{msl})$. The majority of the soil type is alluvial and covers about $42 \%$ of the basin area, whereas calcareous Seirozemic soils contribute a minimum with about $0.5 \%$ of the basin area. Landuse in the basin can be broadly classified as cultivable $(60.0 \%)$, non-arable $(27.5 \%)$ and forest land $(12.5 \%)$. Out of a total cultivable land (i.e. $60 \%$ ), actual cultivable land is only $51.9 \%$ and total habited land is approximately $2.9 \%$. Forest land in the basin pertains mainly to upper Himalayan catchments $(81.4 \%)$.

\section{Data Processing}

The climatic series subjected to the analysis are: (i) annual rainfall; (ii) monsoon and non-monsoon rainfall; (iii) annual rainydays; (iv) monsoon and non-monsoon rainydays; (v) onset of effective monsoon (OEM); and (vi) annual aridity index (AI). For rainfall data, one degree grid data of daily rainfall for the period 1951 to 2002 maintained by the India Meteorological Department (IMD) was used. Sixty five raingrids points that fall under the Yamuna basin with $1^{\circ}$ buffer were used in the analysis. The monsoon rainfall was derived from the daily data for the period July to October and rest of

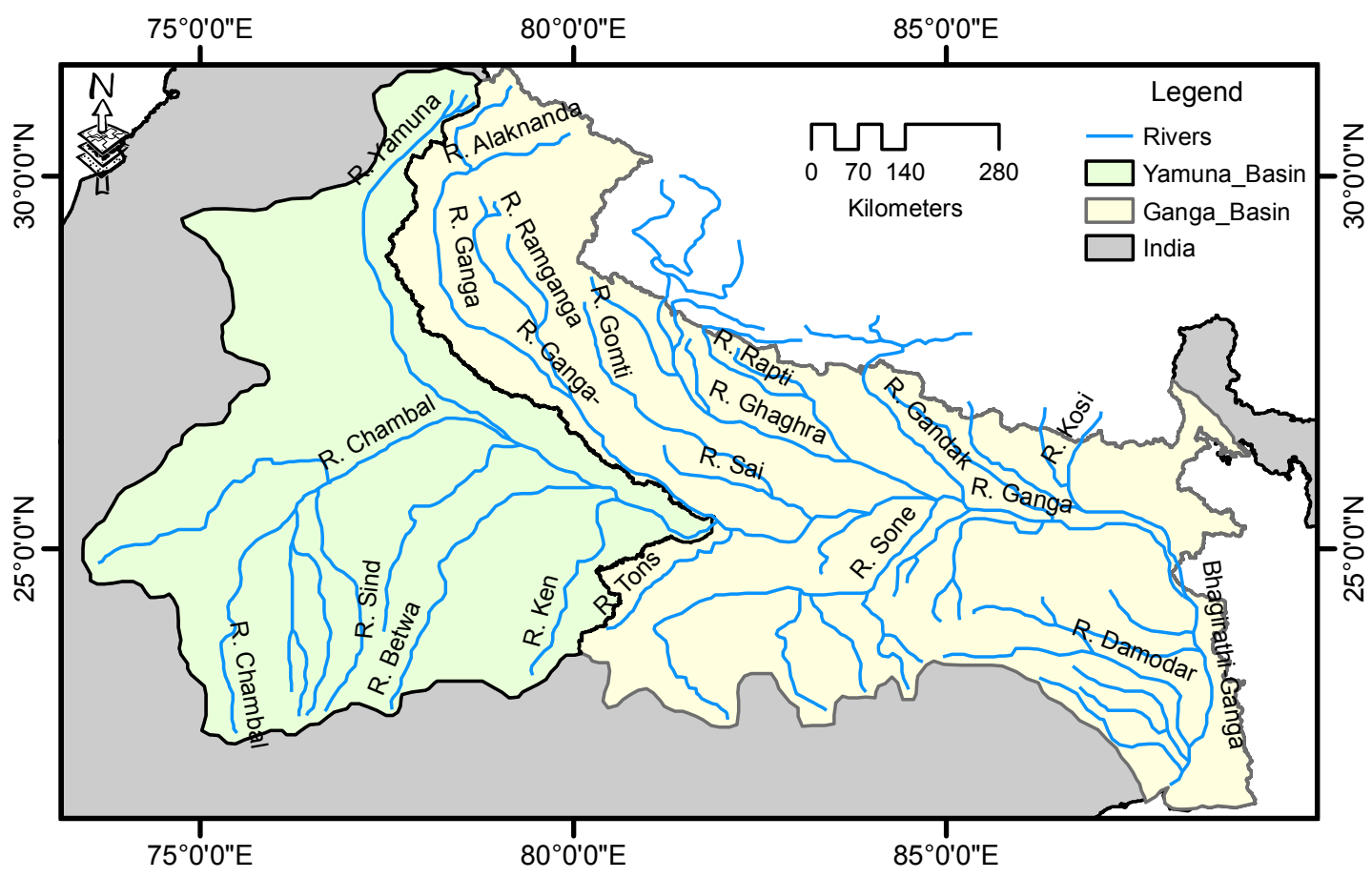

Fig. (1). Ganga basin including Yamuna river basin. 
the period was considered as non-monsoon. The OEM, an important governing agro-climatic parameter for planning of kharif crops was estimated using the Ashokraj criteria [96], which uses the daily rainfall and potential evapotranspiration data. The potential evapotranspiration was estimated using the Thornthwaite method [97]. A seven days rainfall spell satisfying the following conditions are terms as OEM. These conditions are: (i) first day rainfall in the seven days spells should be more than evaporation of that particular day; (ii) a day with-more than $3 \mathrm{~mm}$ of rainfall is considered to be a rainy day; (iii) total rainfall during the seven days spell is more than $(3 \times$ PET +10$) \mathrm{mm}$; and (iv) at least four out of seven days are rainy days.

The aridity index or AI was estimated following the procedure of United Nations Environment Programme [98] as:

$A I=(R / P E T) \times 100 \%$

where, $A I$ is the aridity index $(\%), R$ is the annual rainfall (mm) and $P E T$ is the annual potential evapotranspiration (mm). $A I$ values below $100 \%$ shows annual moisture deficit in average climatic conditions.

The spatial distribution pattern of these hydro-climatic parameters (viz. annual mean, monsoon mean and non monsoon mean rainfall; annual mean, monsoon mean and nonmonsoon mean rainydays; mean OEM; and mean aridity index) is shown in Fig. (2).

\section{RESULTS AND DISCUSSIONS}

\section{Persistence}

Persistence is evident in long time series of climatic observations characterized by a positive serial correlation. Significant negative $r_{1}$ are very likely to be indicative of highfrequency oscillations, whereas significant positive $r_{1}$ is likely to be indicative of low-frequency fluctuations and persistence in climatic series. This feature will be further elaborated in following section (i.e. 'periodicity'). In the study, serial correlation for all the lags (i.e. $L=0$ to $m$ ) were computed for all the grid points. However, serial correlation coefficients up to lag 3 was assessed. Serial correlation coefficient up to lag-3 is plotted for all the climatic variables except non-monsoon, although all the variables were analyzed. These plots are shown in Figs. (3 to 5), which give the spatial distributions pattern of lag-1 to lag-3 serial correlation coefficients for the considered variables over the Yamuna river basin. A regularized spline method was used as an interpolation technique to produce the spatial distribution pattern of the variables.

It $s$ evident from the Figs. (3 to 5 ) that most of the grid point data shows statistically insignificant serial correlation coefficient (SC) for all the hydro-climatic variables (i.e. annual, monsoon and non monsoon ranfall; annual, monsoon and non monsoon rainydays; OEM and aridity index). However, few grid data of annual and monsoon rainfall near the central and northern part of the basin shows the existence of persistence characterized by significant lag-1 SC; whereas, few grid data points in the south-east part of the basin shows high frequency variability as characterized by significant negative lag 1-SC (Fig. 3). The spatial distribution of lag 1$\mathrm{SC}$ of non monsoon (Fig. 4) indicated the presence of persistence in the few grid data in the northern part of the basin.
Lag-1 SC of annual rainfall and aridity index shows the similar distribution pattern, which might be due to the more dependence of aridity index on annual rainfall (Figs. 3 and 5).

Based on Figs. (3 to 5), a little positive spatial coherence characterized by lag-1 SC was identified for annual and monsoon rainfall, annual rainydays and aridity index. Looking into the Figs. (3 to 5) and by comparing the spatial pattern of lag-2 SC with the lag-1 SC, it was indicated that coherent area of significant positive lag-2 SC are greater than that of the lag-1. The lag-2 SC coefficients are mostly positive but insignificant for all the variables except for the nonmonsoon rainfall, non-monsoon rainydays and OEM. On the other hand, by analyzing the lag-3 SC of the hydro-climatic variables, it was evident that the percentage coherent area is significantly reduced for all the variables. However, it is increase in case of non-monsoon rainfall, non-monsoon rainydays and OEM. Apart from this, detailed table of the serial correlation coefficients up to lag-3 are also prepared for all the variables. But, serial correlation coefficients up to lag-3 are presented for monsoon rainfall, rainydays and OEM only (Tables 1 to 3 ), though the summarized table (Table 4) was prepared to visualize the overall temporal characteristics of the variables.

\section{Trend Analysis}

In the trend analysis, time series of the entire variable from 1951 to 2002 were subjected to three non-parametric statistical tests, viz. Mann-Kendall test, Modified MannKendall test and Mann-Kendall test with pre-whitening of series. Two later tests are basically designed for the series having significant lag-1 SC. The comparative results were obtained from all the three tests for all the considered variables. However, the sample results of trend analysis for monsoon rainfall and OEM are presented (Tables 5 - 6). These Tables (Table 5 - 6) also include the value of lag-1 SC along with their lower and upper limits at $95 \%$ confidence level. Based on Tables 5 and 6, it is apparent that the times series with significant negative lag-1 SC do not have the significant trend.

The spatial pattern of lag-1 SC of the hydro-climatic variables is depicted in Figs. ( $\mathbf{3}$ to $\mathbf{5}$ ). The summarized statistics of trend analysis is given in Table 7. Though, the trend results were produced using all the tests but spatial pattern of Z-statistics was presented using the results obtained from modified Mann-Kendall test. For pattern analysis, regularized spline method was used for interpolation of the data. The spatial pattern of the trend statistics for the hydroclimatic variables is shown in Fig. (6) (annual, monsoon, and non-monsoon rainfall; and annual, monsoon, and nonmonsoon rainydays) and Fig. (7) (OEM and aridity index). The patterns ware classified based on the $90 \%$ confidence level (i.e. $Z<-1.645 ;-1.645<Z<0.0 ; 0.0<Z<1.645$; and $Z>1.645)$. These interval $(Z<-1.645 ;-1.645<Z<0.0 ; 0.0$ $<Z<1.645$; and $Z>1.645)$ shows the significant negative trend, insignificant negative trend, insignificant positive trend, and significant positive trend at $90 \%$ confidence interval, respectively.

Based on the analysis (Fig. 6 and Table 7), it can be observed that annual rainfall and monsoon rainfall shows a overall declining trend though the scattered patches of the basin shows insignificant rising trend. The trend statistics for 

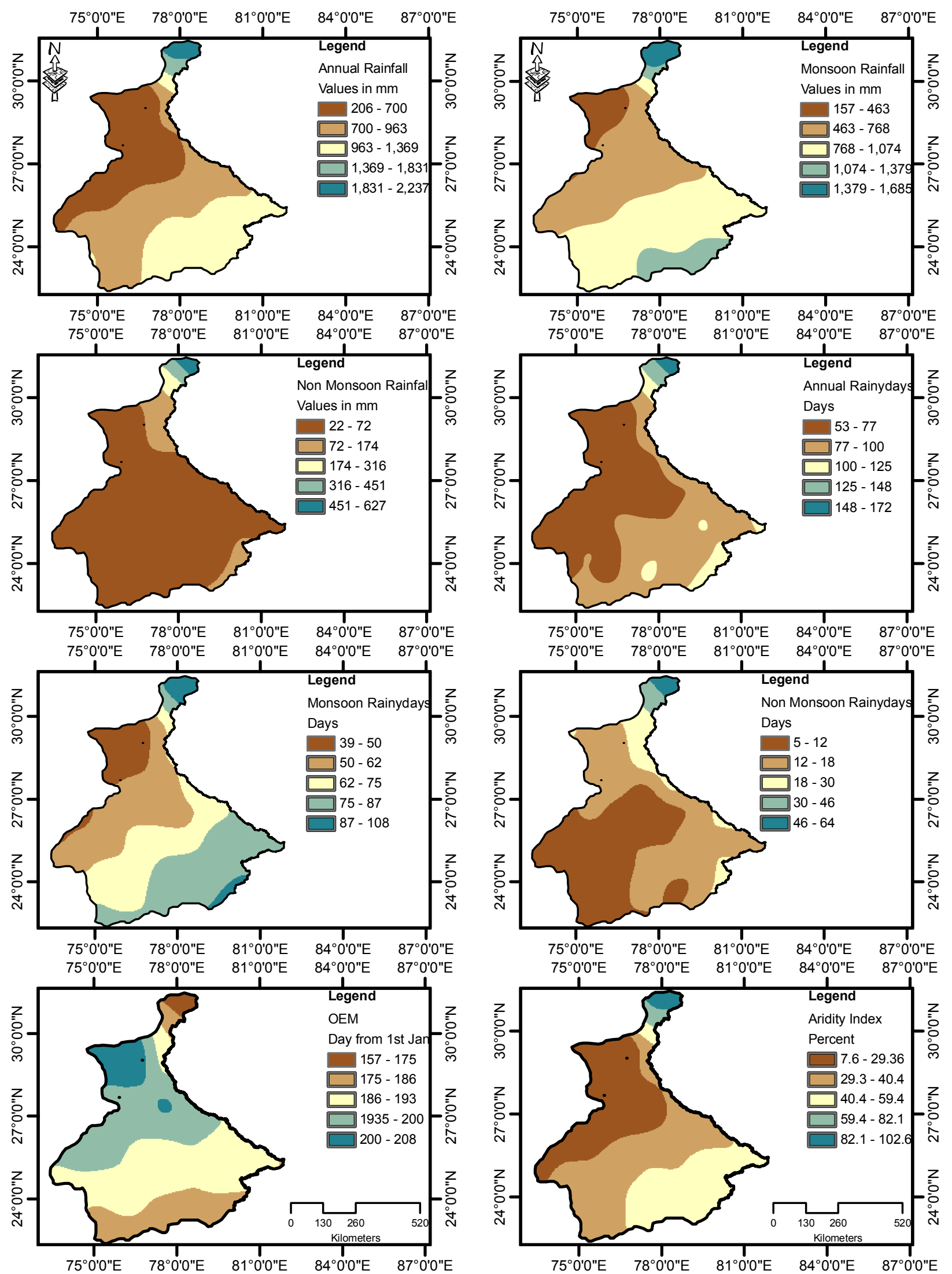

Fig. (2). Spatial distribution pattern of mean hydro-climatic parameters in Yamuna river basin. 

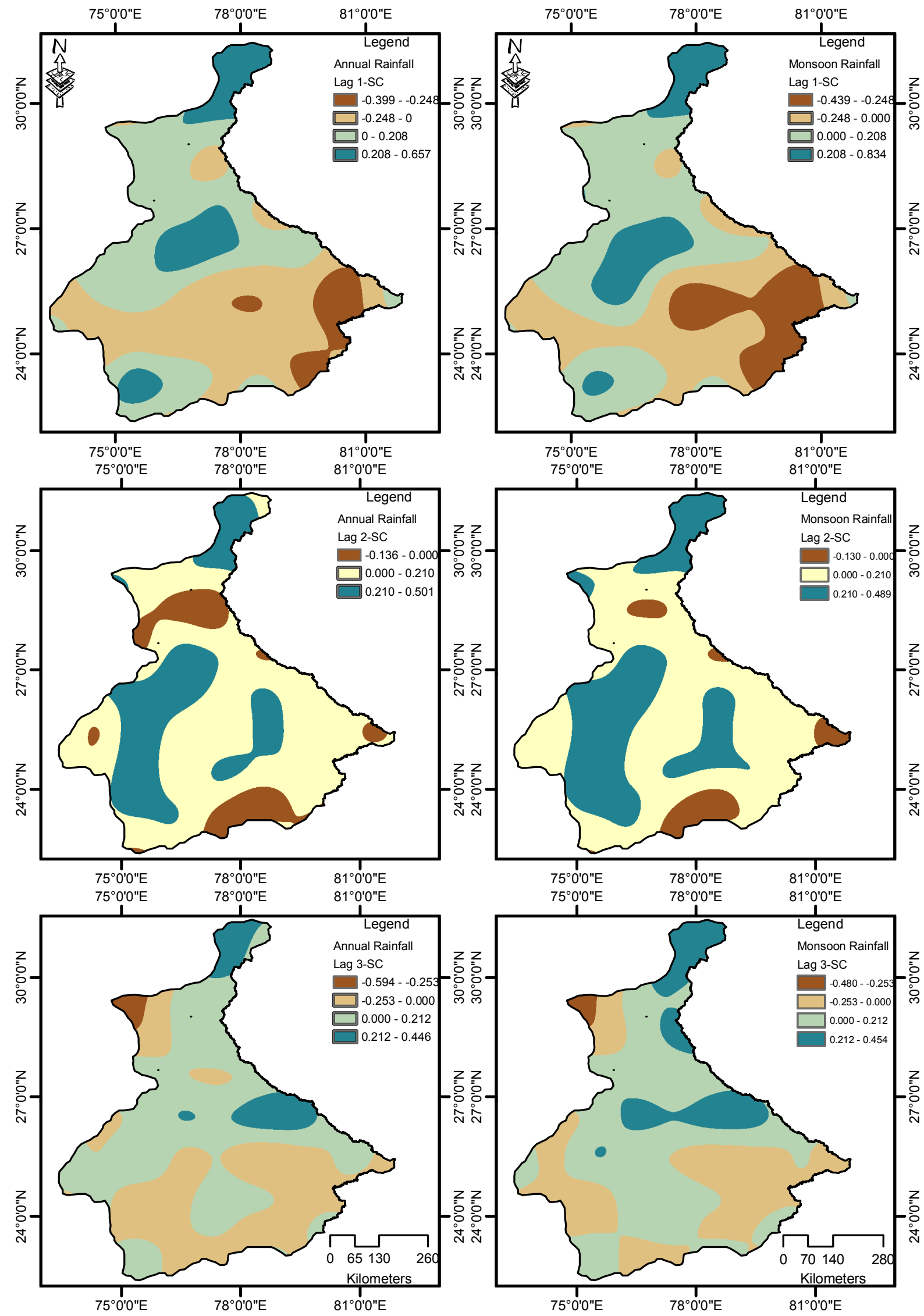

Fig. (3). Spatial distribution pattern of serial correlation of annual mean and monsoon mean rainfall up to lag 3. 

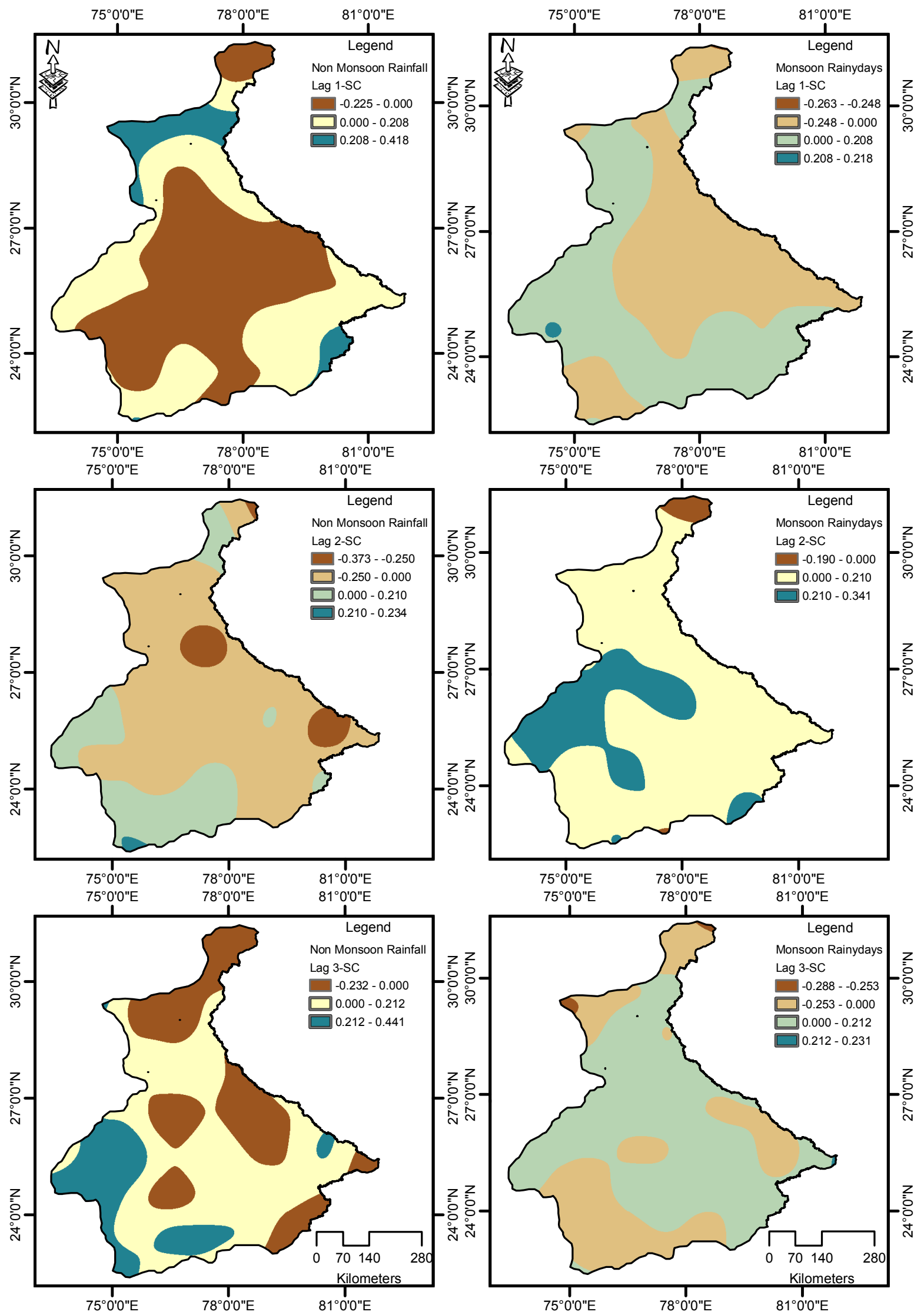

Fig. (4). Spatial distribution pattern of serial correlation of non-monsoon rainfall and monsoon rainydays up to lag 3. 

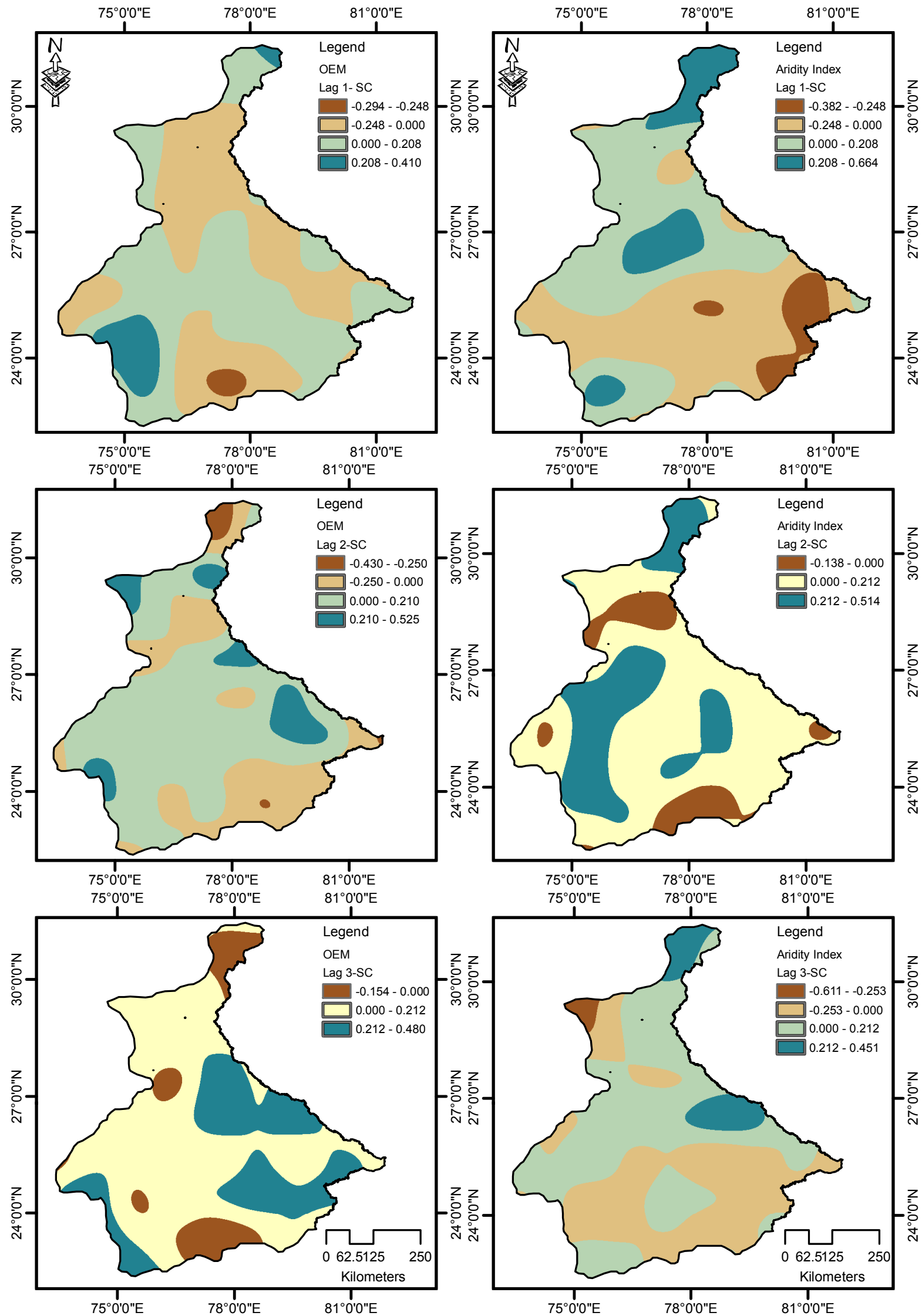

Fig. (5). Spatial distribution pattern of serial correlation of OEM and aridity index up to lag 3. 
Table 1. Results of Serial Correlation (Lag 1 to 3) and Power Spectrum Analysis for Monsoon Rainfall

\begin{tabular}{|c|c|c|c|c|c|c|c|c|c|c|c|c|c|c|c|}
\hline \multirow{2}{*}{ S.No. } & \multirow{2}{*}{$\mathbf{r} 1$} & \multirow{2}{*}{$\mathbf{r} 2$} & \multirow{2}{*}{ r3 } & \multirow{2}{*}{$\mathbf{L}$} & \multicolumn{2}{|c|}{ Cycles } & \multirow{2}{*}{ Cont. } & \multirow{2}{*}{ S.No. } & \multirow{2}{*}{ r1 } & \multirow{2}{*}{$\mathbf{r} 2$} & \multirow{2}{*}{ r3 } & \multirow{2}{*}{$\mathbf{L}$} & \multicolumn{2}{|c|}{ Cycles } & \multirow{2}{*}{ Cont. } \\
\hline & & & & & $90 \%$ & $95 \%$ & & & & & & & $90 \%$ & $95 \%$ & \\
\hline \multirow[t]{2}{*}{1} & 0.00 & -0.18 & -0.18 & 7 & 4.9 & & WN & 31 & -0.27 & 0.25 & -0.10 & 13 & 2.6 & & WN \\
\hline & & & & 8 & 4.3 & & & & & & & 14 & & 2.4 & \\
\hline 2 & 0.05 & -0.01 & 0.04 & 2 & 17.0 & & WN & & & & & 15 & & 2.3 & \\
\hline 3 & 0.05 & 0.02 & 0.08 & 2 & 17.0 & & WN & & & & & 16 & 2.1 & & \\
\hline 4 & -0.09 & 0.11 & -0.05 & & & & WN & 32 & -0.25 & 0.10 & -0.08 & 14 & & 2.4 & WN \\
\hline 5 & -0.12 & -0.07 & -0.05 & & & & WN & & & & & 15 & & 2.3 & \\
\hline 6 & 0.40 & 0.37 & 0.42 & 12 & 2.8 & & $\mathrm{RN}$ & 33 & -0.41 & 0.07 & 0.00 & 13 & & 2.6 & WN \\
\hline 7 & -0.04 & 0.03 & -0.12 & & & & & & & & & 14 & & 2.4 & \\
\hline \multirow[t]{2}{*}{8} & -0.04 & -0.02 & 0.18 & 11 & 3.1 & & $\mathrm{RN}$ & & & & & 15 & & 2.3 & \\
\hline & & & & 12 & & 2.8 & WN & 34 & -0.02 & -0.06 & -0.06 & 7 & 4.9 & & $\mathrm{WN}$ \\
\hline 9 & -0.05 & 0.13 & 0.02 & 2 & & 17.0 & & 35 & -0.12 & 0.11 & -0.04 & 15 & & 2.3 & $\mathrm{WN}$ \\
\hline \multirow[t]{3}{*}{10} & 0.22 & 0.24 & 0.01 & 1 & 34.0 & & & 36 & 0.00 & 0.02 & 0.04 & & & & WN \\
\hline & & & & 2 & & 17.0 & $\mathrm{WN}$ & 37 & 0.20 & 0.18 & -0.07 & 1 & & 34.0 & WN \\
\hline & & & & 3 & 11.3 & & & & & & & 2 & & 17.0 & \\
\hline \multirow[t]{2}{*}{11} & 0.15 & 0.23 & 0.01 & 2 & & 17.0 & WN & 38 & 0.12 & 0.28 & 0.09 & 1 & 34.0 & & $\mathrm{WN}$ \\
\hline & & & & 3 & & 11.3 & & & & & & 2 & 17.0 & & \\
\hline 12 & -0.03 & -0.03 & 0.04 & & & & WN & 39 & 0.35 & 0.30 & 0.27 & 2 & 17.0 & & $\mathrm{RN}$ \\
\hline 13 & -0.02 & -0.11 & -0.02 & & & & WN & & & & & 12 & 2.8 & & \\
\hline \multirow[t]{2}{*}{14} & -0.34 & 0.07 & 0.01 & 14 & & 2.4 & WN & 40 & 0.26 & 0.14 & 0.22 & 12 & & 2.8 & $\mathrm{RN}$ \\
\hline & & & & 15 & & 2.3 & & & & & & 13 & & 2.6 & \\
\hline 15 & -0.18 & -0.02 & 0.12 & & & & WN & 41 & 0.11 & 0.23 & 0.31 & 1 & 34.0 & & $\mathrm{WN}$ \\
\hline 16 & -0.14 & 0.10 & -0.01 & & & & & 42 & 0.02 & 0.12 & 0.27 & & & & WN \\
\hline 17 & 0.07 & 0.05 & -0.01 & 2 & 17.0 & & $\mathrm{WN}$ & 43 & -0.14 & 0.06 & 0.06 & 13 & & 2.6 & \\
\hline \multirow[t]{2}{*}{18} & -0.20 & 0.15 & -0.03 & 14 & 2.4 & & WN & & & & & 14 & & 2.4 & \\
\hline & & & & 15 & & 2.3 & & 44 & -0.13 & 0.15 & 0.04 & 13 & 2.6 & & WN \\
\hline \multirow[t]{5}{*}{19} & -0.08 & 0.39 & -0.11 & 2 & & 17.0 & WN & & & & & 14 & & 2.4 & \\
\hline & & & & 3 & & 11.3 & & & & & & 15 & 2.3 & & \\
\hline & & & & 15 & 2.3 & & & 45 & 0.40 & 0.30 & 0.13 & 13 & 2.6 & & $\mathrm{RN}$ \\
\hline & & & & 16 & & 2.1 & & 46 & 0.18 & 0.04 & 0.19 & 2 & & 17.0 & WN \\
\hline & & & & 17 & 2.0 & & & & & & & 3 & 11.3 & & \\
\hline \multirow[t]{2}{*}{20} & -0.04 & 0.17 & 0.13 & 2 & & 17.0 & WN & 47 & 0.11 & 0.24 & 0.10 & 2 & 17.0 & & WN \\
\hline & & & & 3 & & 11.3 & & & & & & 3 & 11.3 & & \\
\hline 21 & -0.22 & 0.23 & 0.13 & 2 & 17.0 & & WN & 48 & 0.14 & 0.15 & 0.06 & 4 & 8.5 & & WN \\
\hline & & & & 3 & 11.3 & & & & & & & 5 & 6.8 & & \\
\hline & & & & 13 & 2.6 & & & 49 & -0.10 & -0.01 & 0.13 & 12 & 2.8 & & $\mathrm{WN}$ \\
\hline & & & & 14 & & 2.4 & & 50 & -0.07 & 0.06 & 0.09 & 13 & & 2.6 & WN \\
\hline
\end{tabular}


Table 1. contd....

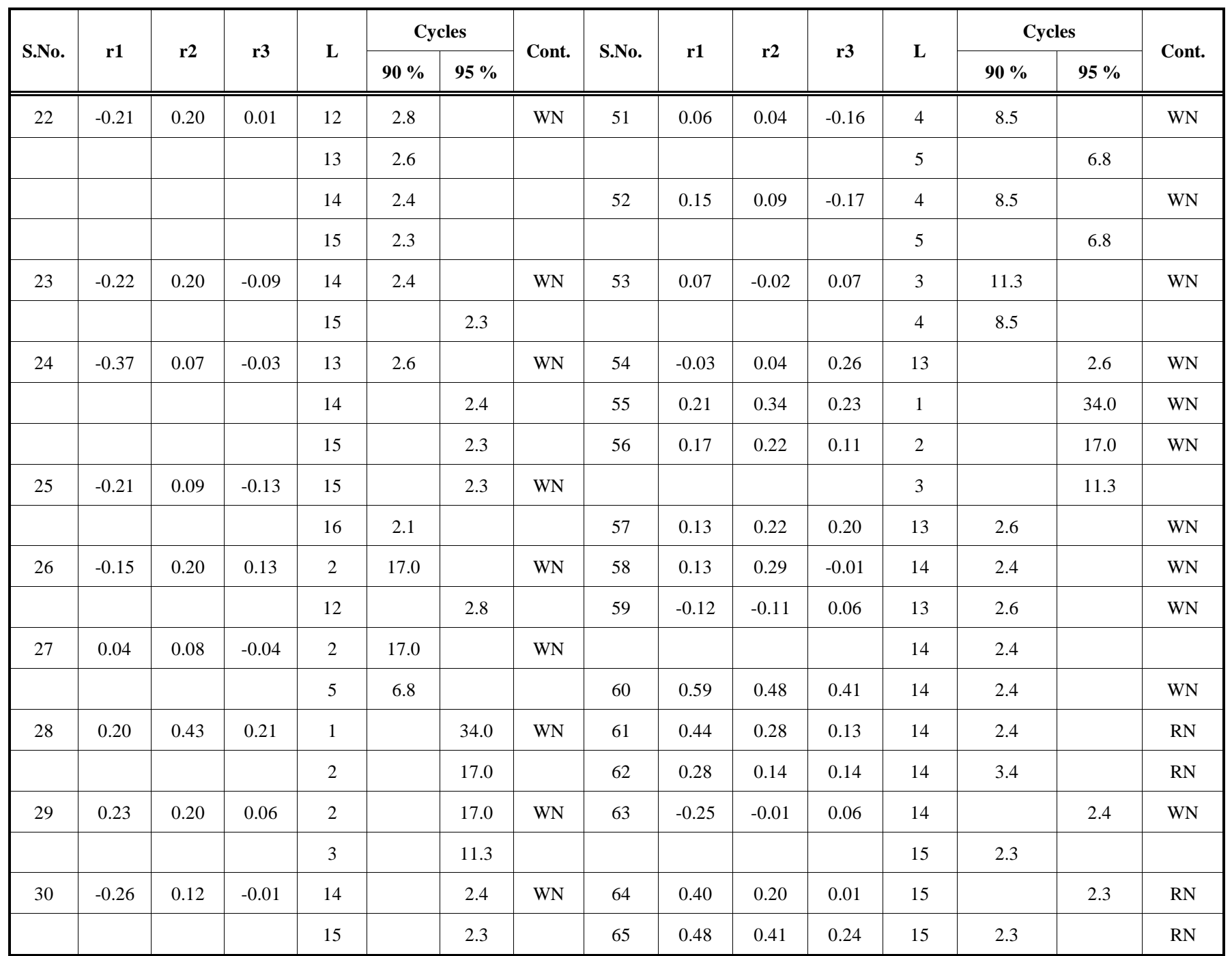

$\mathrm{r}_{1}=$ lag-1 SC, $\mathrm{r}_{2}=$ lag-2 SC, $\mathrm{r}_{3}=$ lag-3 SC, L = lag corresponding to significant spectral estimates, Cycles = periodicity $(2 \mathrm{~m} / \mathrm{L})$, Cont. = null continuum, WN = white noise, RN = Markov red noise

Table 2. Results of Serial Correlation (Lag 1 to 3) and Power Spectrum Analysis for Monsoon Rainydays

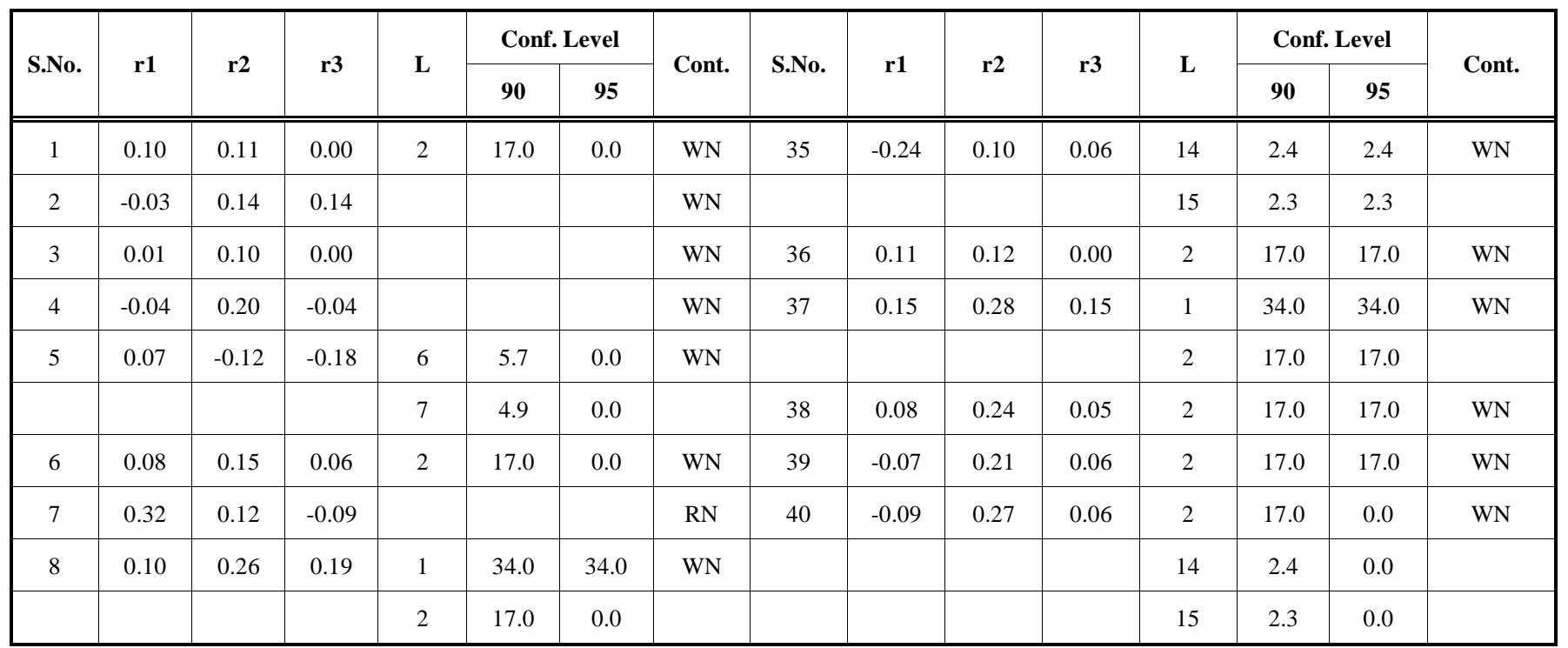


Table 2. contd....

\begin{tabular}{|c|c|c|c|c|c|c|c|c|c|c|c|c|c|c|c|}
\hline S.No. & r1 & r2 & r3 & $\mathbf{L}$ & \multicolumn{2}{|c|}{ Conf. Level } & Cont. & S.No. & r1 & r2 & r3 & $\mathbf{L}$ & \multicolumn{2}{|c|}{ Conf. Level } & Cont. \\
\hline & & & & 13 & 2.6 & 0.0 & & 41 & -0.07 & 0.18 & 0.00 & 15 & 2.3 & 0.0 & WN \\
\hline 9 & -0.04 & 0.15 & -0.01 & 12 & 2.8 & 0.0 & WN & 42 & -0.03 & 0.11 & -0.01 & 5 & 6.8 & 0.0 & WN \\
\hline 10 & -0.07 & 0.16 & -0.13 & & & & WN & & & & & 14 & 2.4 & 0.0 & \\
\hline 12 & 0.04 & 0.18 & 0.01 & 2 & 17.0 & 17.0 & WN & 44 & 0.06 & 0.05 & 0.08 & 5 & 6.8 & 0.0 & $\mathrm{WN}$ \\
\hline 13 & 0.02 & 0.03 & -0.08 & 5 & 6.8 & 0.0 & WN & 45 & 0.13 & 0.12 & 0.18 & 1 & 34.0 & 34.0 & WN \\
\hline \multirow[t]{2}{*}{14} & 0.09 & 0.27 & 0.10 & 1 & 34.0 & 0.0 & WN & & & & & 2 & 17.0 & 17.0 & \\
\hline & & & & 2 & 17.0 & 17.0 & & 46 & 0.19 & 0.17 & 0.13 & 1 & 34.0 & 34.0 & WN \\
\hline 16 & -0.01 & 0.01 & 0.08 & 12 & 2.8 & 2.8 & WN & & & & & 3 & 11.3 & 0.0 & \\
\hline 17 & 0.04 & 0.09 & 0.02 & 2 & 17.0 & 0.0 & WN & 48 & -0.08 & 0.12 & 0.11 & & & & WN \\
\hline \multirow[t]{3}{*}{18} & 0.21 & 0.22 & -0.03 & 1 & 34.0 & 0.0 & WN & 49 & -0.13 & 0.09 & 0.06 & 14 & 2.4 & 2.4 & WN \\
\hline & & & & 2 & 17.0 & 17.0 & & 50 & -0.01 & 0.14 & 0.11 & 2 & 17.0 & 0.0 & WN \\
\hline & & & & 3 & 11.3 & 0.0 & & & & & & 14 & 2.4 & 0.0 & \\
\hline 19 & 0.07 & 0.07 & -0.13 & 2 & 17.0 & 0.0 & WN & 51 & 0.14 & 0.07 & -0.01 & 2 & 17.0 & 0.0 & WN \\
\hline 20 & 0.03 & 0.28 & 0.08 & 2 & 17.0 & 17.0 & WN & & & & & 5 & 6.8 & 0.0 & \\
\hline 25 & 0.01 & 0.11 & 0.18 & 14 & 2.4 & 0.0 & WN & 55 & 0.10 & 0.11 & 0.16 & & & & WN \\
\hline 26 & 0.09 & 0.20 & 0.09 & 1 & 34.0 & 34.0 & WN & 56 & -0.01 & 0.19 & -0.02 & 2 & 17.0 & 0.0 & WN \\
\hline \multirow[t]{2}{*}{27} & 0.16 & 0.28 & 0.06 & 1 & 34.0 & 34.0 & WN & & & & & 3 & 11.3 & 0.0 & \\
\hline & & & & 2 & 17.0 & 17.0 & & 57 & 0.04 & 0.16 & 0.06 & 2 & 17.0 & 0.0 & WN \\
\hline \multirow[t]{2}{*}{28} & 0.07 & 0.32 & 0.02 & 1 & 34.0 & 34.0 & WN & 58 & 0.37 & 0.28 & 0.08 & & & & $\mathrm{RN}$ \\
\hline & & & & 2 & 17.0 & 17.0 & & 59 & 0.05 & 0.16 & 0.09 & 1 & 34.0 & 0.0 & WN \\
\hline 29 & -0.05 & 0.11 & -0.01 & 14 & 2.4 & 0.0 & WN & 60 & 0.01 & 0.08 & -0.06 & & & & WN \\
\hline 30 & -0.06 & 0.17 & 0.00 & 14 & 2.4 & 2.4 & WN & 61 & 0.08 & 0.07 & -0.10 & 5 & 6.8 & 0.0 & WN \\
\hline 31 & -0.08 & 0.20 & 0.10 & 14 & 2.4 & 0.0 & WN & 62 & 0.05 & -0.02 & -0.01 & & & & WN \\
\hline 32 & -0.03 & 0.11 & 0.05 & & & & WN & 63 & -0.18 & 0.27 & -0.09 & 15 & 2.3 & 0.0 & WN \\
\hline 33 & -0.05 & 0.05 & -0.06 & & & & WN & & & & & 16 & 2.1 & 0.0 & \\
\hline \multirow[t]{2}{*}{34} & -0.01 & 0.12 & 0.15 & 14 & 2.4 & 0.0 & WN & 64 & 0.28 & 0.10 & 0.03 & & & & $\mathrm{RN}$ \\
\hline & & & & & & & & 65 & 0.43 & 0.36 & 0.27 & 14 & 2.4 & 0.0 & $\mathrm{RN}$ \\
\hline
\end{tabular}

$\mathrm{r}_{1}=$ lag-1 SC, $\mathrm{r}_{2}=$ lag-2 SC, $\mathrm{r}_{3}=$ lag-3 SC, $\mathrm{L}=$ lag corresponding to significant spectral estimates, Cycles $=$ periodicity $(2 \mathrm{~m} / \mathrm{L}), \mathrm{Cont} .=$ null continuum, $\mathrm{WN}=$ white noise, $\mathrm{RN}=$ Markov red noise 
Table 3. Results of Serial Correlation (Lag 1 to 3) and Power Spectrum Analysis for OEM

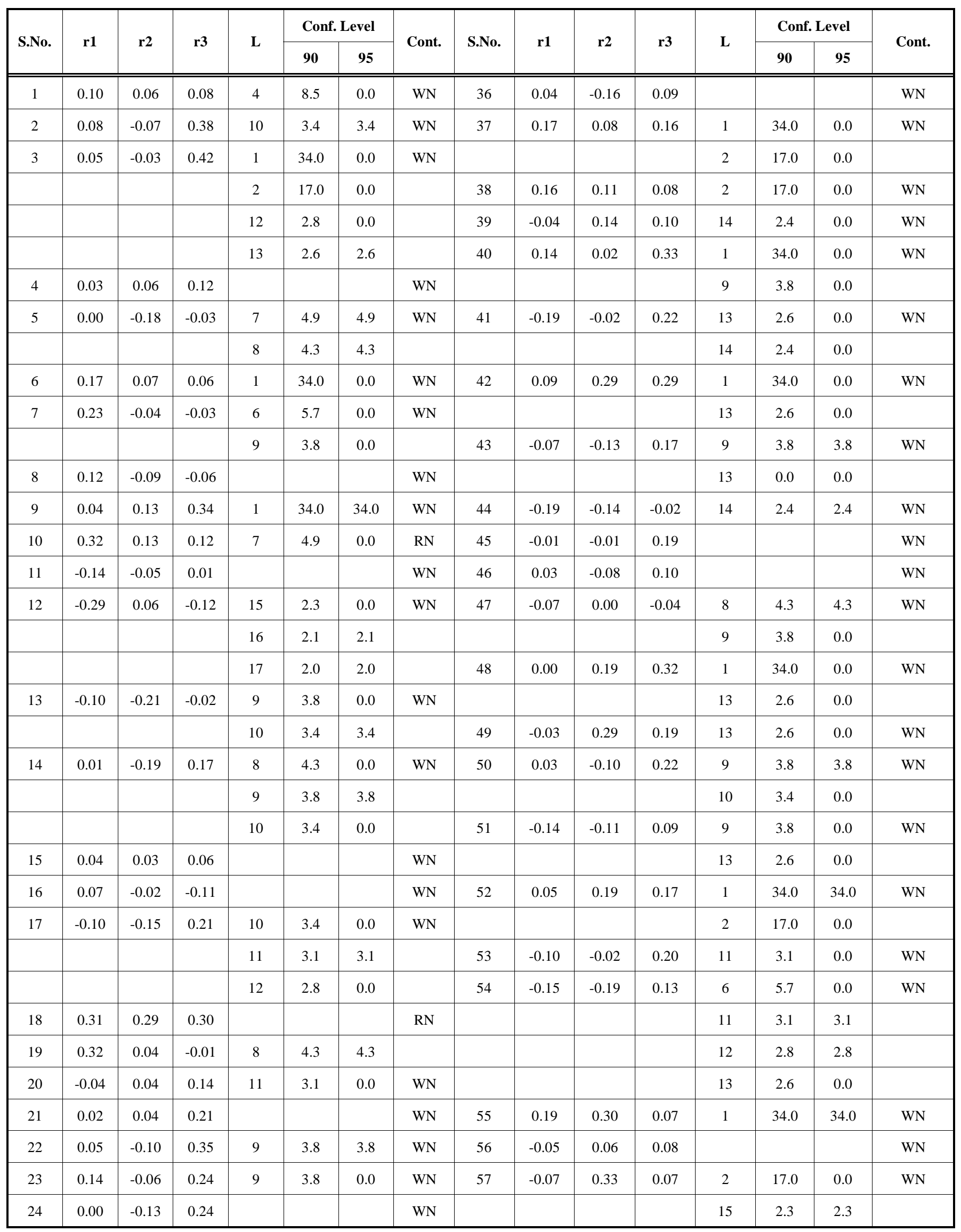


Table 3. contd....

\begin{tabular}{|c|c|c|c|c|c|c|c|c|c|c|c|c|c|c|c|}
\hline \multirow{2}{*}{ S.No. } & \multirow{2}{*}{ r1 } & \multirow{2}{*}{ r2 } & \multirow{2}{*}{ r3 } & \multirow{2}{*}{$\mathbf{L}$} & \multicolumn{2}{|c|}{ Conf. Level } & \multirow{2}{*}{ Cont. } & \multirow{2}{*}{ S.No. } & \multirow{2}{*}{ r1 } & \multirow{2}{*}{$\mathbf{r} 2$} & \multirow{2}{*}{ r3 } & \multirow{2}{*}{$\mathbf{L}$} & \multicolumn{2}{|c|}{ Conf. Level } & \multirow{2}{*}{ Cont. } \\
\hline & & & & & 90 & 95 & & & & & & & 90 & 95 & \\
\hline \multirow[t]{2}{*}{25} & 0.17 & -0.15 & 0.18 & 8 & 4.3 & 4.3 & WN & 58 & 0.02 & 0.03 & -0.25 & 4 & 8.5 & 8.5 & WN \\
\hline & & & & 9 & 3.8 & 3.8 & & & & & & 5 & 6.8 & 6.8 & \\
\hline 26 & -0.16 & -0.05 & -0.08 & 10 & 3.4 & 0.0 & WN & 59 & 0.01 & 0.13 & 0.08 & 13 & 2.6 & 0.0 & WN \\
\hline 27 & -0.11 & 0.03 & 0.15 & 13 & 2.6 & 2.6 & WN & 60 & 0.05 & -0.28 & -0.04 & 8 & 4.3 & 4.3 & WN \\
\hline 28 & 0.12 & 0.10 & 0.15 & & & & WN & & & & & 9 & 3.8 & 3.8 & \\
\hline 29 & 0.03 & 0.12 & 0.14 & 14 & 2.4 & 2.4 & WN & 61 & 0.12 & 0.12 & -0.13 & 2 & 17.0 & 0.0 & WN \\
\hline 30 & 0.03 & 0.09 & 0.10 & 14 & 2.4 & 0.0 & WN & 62 & 0.16 & -0.03 & 0.02 & & & & WN \\
\hline 31 & 0.10 & 0.13 & 0.22 & & & & WN & 63 & 0.12 & -0.19 & -0.08 & 5 & 6.8 & 0.0 & \\
\hline 32 & -0.10 & 0.26 & 0.14 & 13 & 2.6 & 2.6 & WN & & & & & 6 & 5.7 & 5.7 & WN \\
\hline \multirow[t]{2}{*}{33} & 0.01 & 0.20 & 0.21 & 12 & 2.8 & 0.0 & WN & 64 & -0.06 & -0.19 & 0.08 & 8 & 4.3 & 0.0 & WN \\
\hline & & & & 13 & 2.6 & 2.6 & & & & & & 9 & 3.8 & 3.8 & \\
\hline \multirow[t]{2}{*}{34} & 0.02 & -0.21 & 0.17 & 8 & 4.3 & 0.0 & WN & 65 & -0.04 & -0.14 & 0.13 & 9 & 3.8 & 0.0 & WN \\
\hline & & & & 9 & 3.8 & 0.0 & & & & & & & & & \\
\hline \multirow[t]{2}{*}{35} & -0.12 & -0.25 & 0.20 & 9 & 3.8 & 3.8 & WN & & & & & & & & \\
\hline & & & & 10 & 3.4 & 3.4 & & & & & & & & & \\
\hline
\end{tabular}

$\mathrm{r}_{1}=$ lag-1 SC, $\mathrm{r}_{2}=$ lag-2 SC, $\mathrm{r}_{3}=$ lag-3 SC, L = lag corresponding to significant spectral estimates, Cycles = periodicity $(2 \mathrm{~m} / \mathrm{L})$, Cont. $=$ null continuum, $\mathrm{WN}=$ white noise, $\mathrm{RN}=$ Markov red noise

Table 4. Summarized Result of Persistence Analysis

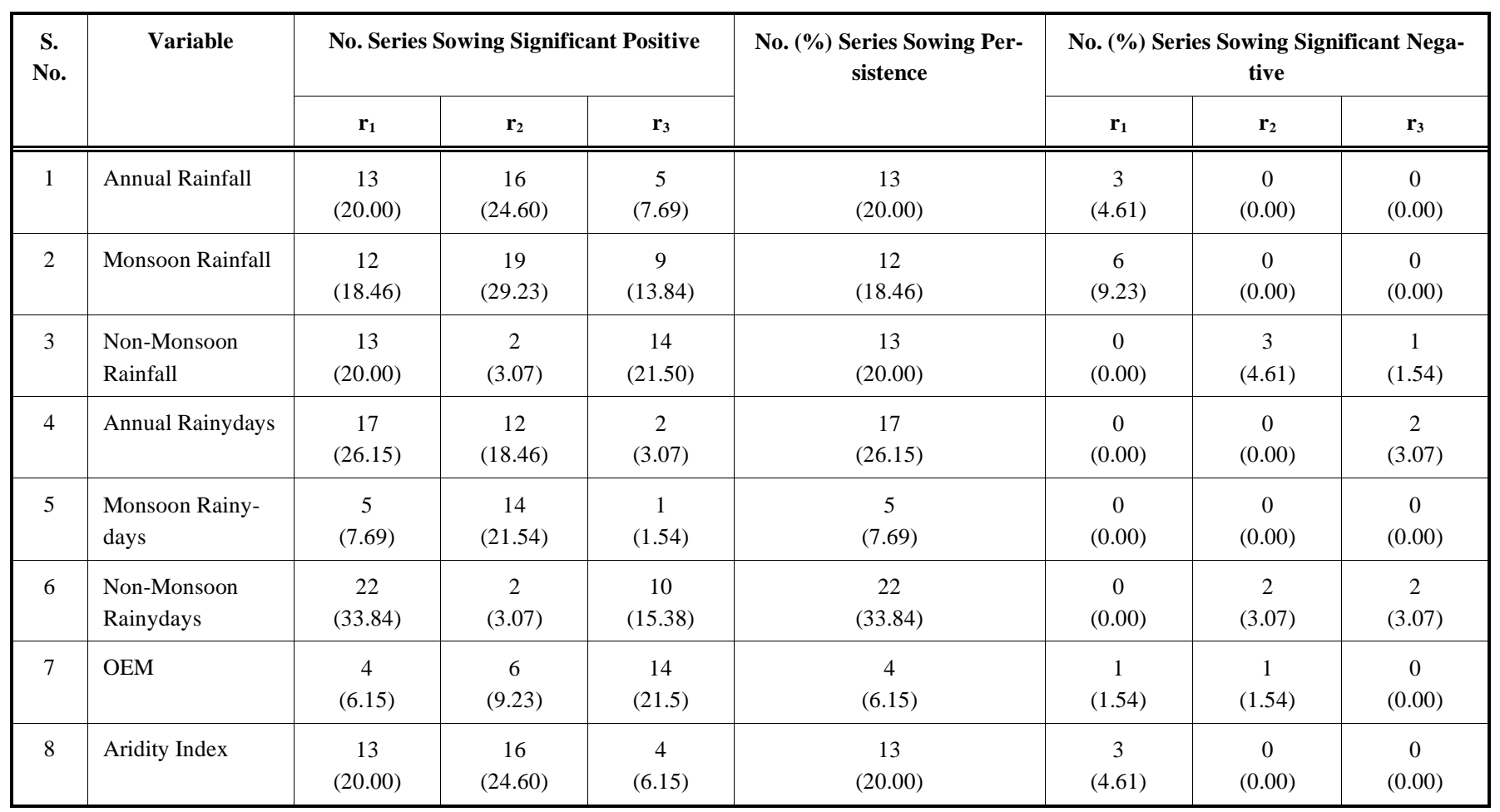

Values in the parenthesis are the percentage of total time series 
Table 5. Lag-1 Serial Correlation and Mann-Kendall's Z-Statistics of Monsoon Rainfall of the Yamuna River Basin $\left[r_{l}(l)=-0.248\right.$ and $\left.r_{I}(u)=0.208\right]$

\begin{tabular}{|c|c|c|c|c|c|c|c|c|c|c|c|}
\hline \multicolumn{2}{|c|}{ Grid Location } & $\mathbf{r}_{1}$ & \multicolumn{3}{|c|}{ Z-MK } & \multicolumn{2}{|c|}{ Grid Location } & $\mathbf{r}_{1}$ & \multicolumn{3}{|c|}{ Z-MK } \\
\hline $22.5 \mathrm{~N}$ & $74.5 \mathrm{E}$ & 0.052 & -0.655 & -0.655 & -0.655 & $25.5 \mathrm{~N}$ & $82.5 \mathrm{E}$ & -0.123 & 1.065 & 1.065 & 1.065 \\
\hline $22.5 \mathrm{~N}$ & $75.5 \mathrm{E}$ & 0.047 & -0.513 & -0.513 & -0.513 & $26.5 \mathrm{~N}$ & $73.5 \mathrm{E}$ & -0.004 & 0.292 & 0.292 & 0.292 \\
\hline $22.5 \mathrm{~N}$ & $77.5 \mathrm{E}$ & -0.121 & -0.702 & -0.702 & -0.702 & $26.5 \mathrm{~N}$ & $75.5 \mathrm{E}$ & 0.119 & -1.405 & -1.405 & -1.405 \\
\hline $22.5 \mathrm{~N}$ & $78.5 \mathrm{E}$ & 0.396 & -4.34 & 0.021 & -3.338 & $26.5 \mathrm{~N}$ & $76.5 \mathrm{E}$ & 0.346 & -1.981 & 0.005 & -2.359 \\
\hline $22.5 \mathrm{~N}$ & $79.5 \mathrm{E}$ & -0.039 & 0.016 & 0.016 & 0.016 & $26.5 \mathrm{~N}$ & $77.5 \mathrm{E}$ & 0.257 & -2.044 & -2.044 & -2.438 \\
\hline $23.5 \mathrm{~N}$ & $76.5 \mathrm{E}$ & 0.152 & -1.302 & -1.302 & -1.302 & $26.5 \mathrm{~N}$ & $81.5 \mathrm{E}$ & -0.128 & -1.413 & -1.413 & -1.413 \\
\hline $23.5 \mathrm{~N}$ & $77.5 \mathrm{E}$ & -0.029 & 1.065 & 1.065 & 1.065 & $27.5 \mathrm{~N}$ & $74.5 \mathrm{E}$ & 0.401 & -1.349 & 0.015 & -1.176 \\
\hline $23.5 \mathrm{~N}$ & $78.5 \mathrm{E}$ & -0.018 & -0.339 & -0.339 & -0.339 & $27.5 \mathrm{~N}$ & $75.5 \mathrm{E}$ & 0.181 & -1.199 & -1.199 & -1.199 \\
\hline $23.5 \mathrm{~N}$ & $79.5 \mathrm{E}$ & -0.344 & -0.813 & 0.061 & -1.239 & $27.5 \mathrm{~N}$ & $76.5 \mathrm{E}$ & 0.105 & -1.933 & -1.933 & -1.933 \\
\hline $23.5 \mathrm{~N}$ & $80.5 \mathrm{E}$ & -0.177 & -0.687 & -0.687 & -0.687 & $27.5 \mathrm{~N}$ & $77.5 \mathrm{E}$ & 0.144 & -2.178 & -2.178 & -2.178 \\
\hline $24.5 \mathrm{~N}$ & $72.5 \mathrm{E}$ & -0.144 & -0.915 & -0.915 & -0.915 & $27.5 \mathrm{~N}$ & $78.5 \mathrm{E}$ & -0.1 & -0.955 & -0.955 & -0.955 \\
\hline $24.5 \mathrm{~N}$ & $78.5 \mathrm{E}$ & -0.211 & -1.176 & -1.176 & -1.176 & $28.5 \mathrm{~N}$ & $78.5 \mathrm{E}$ & 0.211 & -3.717 & -3.717 & -3.764 \\
\hline $24.5 \mathrm{~N}$ & $79.5 \mathrm{E}$ & -0.224 & 0.103 & 0.103 & 0.103 & $29.5 \mathrm{~N}$ & $76.5 \mathrm{E}$ & 0.169 & -1.618 & -1.618 & -1.618 \\
\hline $24.5 \mathrm{~N}$ & $80.5 \mathrm{E}$ & -0.371 & -0.418 & -0.418 & -0.718 & $29.5 \mathrm{~N}$ & $77.5 \mathrm{E}$ & 0.13 & -3.306 & -3.306 & -3.306 \\
\hline $24.5 \mathrm{~N}$ & $81.5 \mathrm{E}$ & -0.21 & 0.86 & 0.86 & 0.86 & $29.5 \mathrm{~N}$ & $78.5 \mathrm{E}$ & 0.125 & -2.044 & -2.044 & -2.044 \\
\hline $25.5 \mathrm{~N}$ & $73.5 \mathrm{E}$ & -0.149 & -0.166 & -0.166 & -0.166 & $30.5 \mathrm{~N}$ & $76.5 \mathrm{E}$ & -0.123 & 0.055 & 0.055 & 0.055 \\
\hline $25.5 \mathrm{~N}$ & $74.5 \mathrm{E}$ & 0.04 & 0.229 & 0.229 & 0.229 & $30.5 \mathrm{~N}$ & $77.5 \mathrm{E}$ & 0.593 & -1.223 & 0.013 & -1.381 \\
\hline $25.5 \mathrm{~N}$ & $75.5 \mathrm{E}$ & 0.202 & -2.951 & -2.951 & -2.951 & $30.5 \mathrm{~N}$ & $78.5 \mathrm{E}$ & 0.444 & -2.517 & 0.046 & -1.996 \\
\hline $25.5 \mathrm{~N}$ & $76.5 \mathrm{E}$ & 0.227 & -1.586 & -1.586 & -1.996 & $31.5 \mathrm{~N}$ & $76.5 \mathrm{E}$ & 0.281 & -1.428 & 0.015 & -1.507 \\
\hline $25.5 \mathrm{~N}$ & $77.5 \mathrm{E}$ & -0.255 & -0.039 & -0.039 & -0.481 & $31.5 \mathrm{~N}$ & $77.5 \mathrm{E}$ & -0.253 & -1.081 & -1.081 & -1.87 \\
\hline $25.5 \mathrm{~N}$ & $78.5 \mathrm{E}$ & -0.272 & -1.207 & 0.009 & -2.123 & $31.5 \mathrm{~N}$ & $78.5 \mathrm{E}$ & 0.395 & 2.888 & 0.04 & 1.728 \\
\hline $25.5 \mathrm{~N}$ & $79.5 \mathrm{E}$ & -0.247 & -1.192 & -1.192 & -1.192 & $31.5 \mathrm{~N}$ & $79.5 \mathrm{E}$ & 0.475 & 1.476 & -0.013 & 0.245 \\
\hline $25.5 \mathrm{~N}$ & $80.5 \mathrm{E}$ & -0.409 & -0.797 & -0.034 & -1.097 & & & & & & \\
\hline
\end{tabular}

$\mathrm{r}_{1}=$ lag-1 SC, Z-MK = Mann-Kendall's Z-statistics, Org = original MK test, Mod = modified MK test, PW = MK test with pre-whitening of data 
Table 6. Lag-1 Serial Correlation and Mann-Kendall's Z-Statistics of OEM of the Yamuna River Basin $\left[r_{I}(l)=-0.248\right.$ and $r_{l}(u)=$ 0.208]

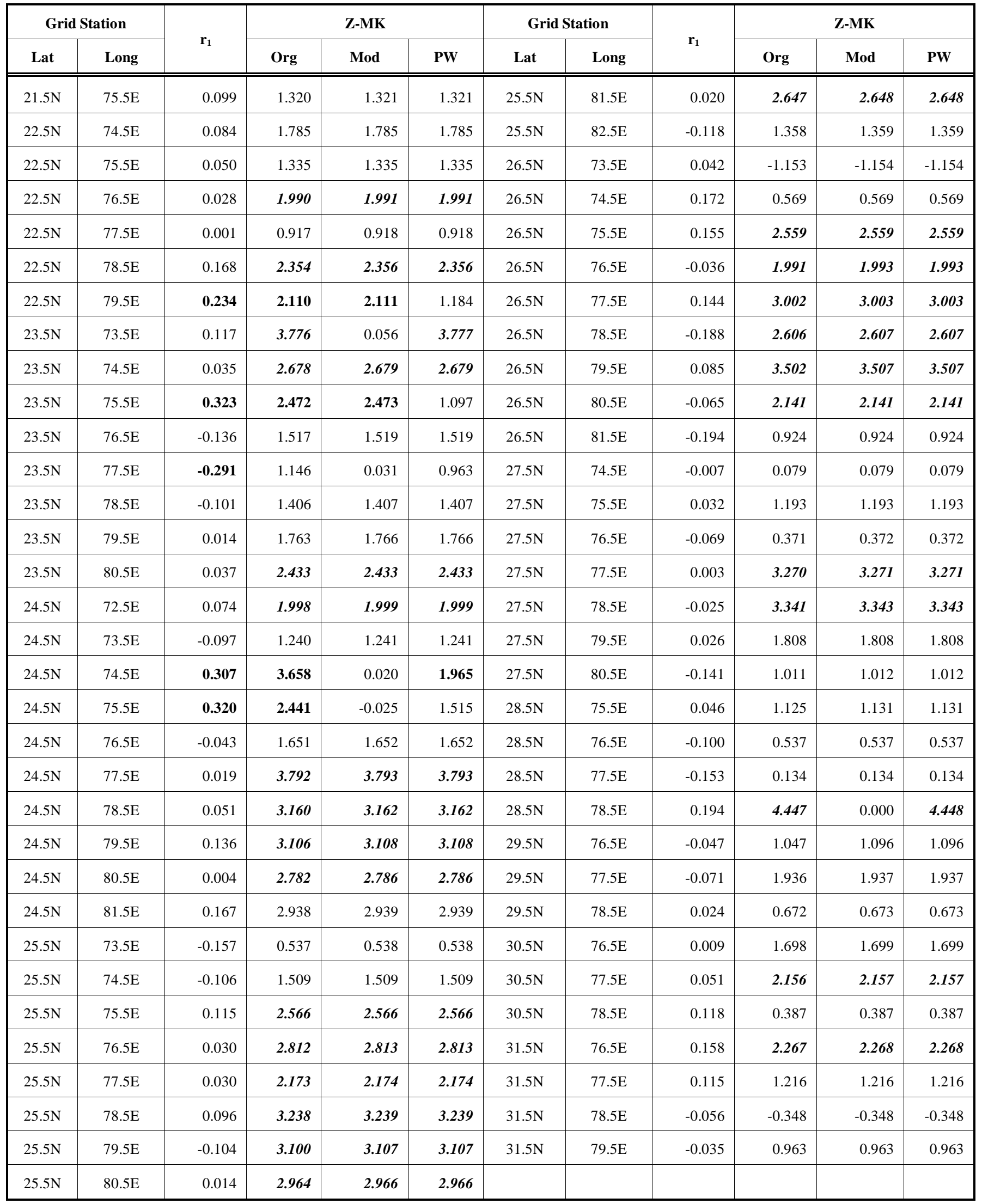


Table 7. Summary of Trend Analysis Based on Modified Mann-Kendall Test

\begin{tabular}{|c|c|c|c|c|c|c|c|c|c|}
\hline $\begin{array}{c}\text { S. } \\
\text { No }\end{array}$ & Variable & \multicolumn{3}{|c|}{ Mean Value } & $\begin{array}{l}\text { No. of Series Indi- } \\
\text { cating significant } \\
\text { lag-1 serial } \\
\text { correlation }\end{array}$ & \multicolumn{4}{|c|}{ No. of Series Indicating Significant } \\
\hline 1 & Annual rainfall & 893.3 & $372.2-1653.5$ & 280.3 & 13 & & $6(8)$ & $59(57)$ & - ve \\
\hline 2 & Monsoon rainfall & 806.8 & $327.0-1568.9$ & 259.7 & 12 & & $8(13)$ & $57(52)$ & - ve \\
\hline 4 & Annual rainydays & 88 & $46.0-160.0$ & 25 & 17 & $4(2)$ & $7(11)$ & $54(52)$ & $-\mathrm{ve}$ \\
\hline 5 & Monsoon rainydays & 70 & $43-96$ & 15 & 5 & & $5(6)$ & $60(59)$ & - ve \\
\hline 6 & Non-monsoon rainydays & 17 & $1-72$ & 14 & 22 & $6(2)$ & $1(2)$ & $58(61)$ & $+\mathrm{ve}$ \\
\hline 7 & OEM & 190 & $173-207$ & 7 & 4 & $29(30)$ & & $36(35)$ & $+\mathrm{ve}$ \\
\hline
\end{tabular}

(Values in the parenthesis are the results from Mann-Kendall with pre-whitening test)
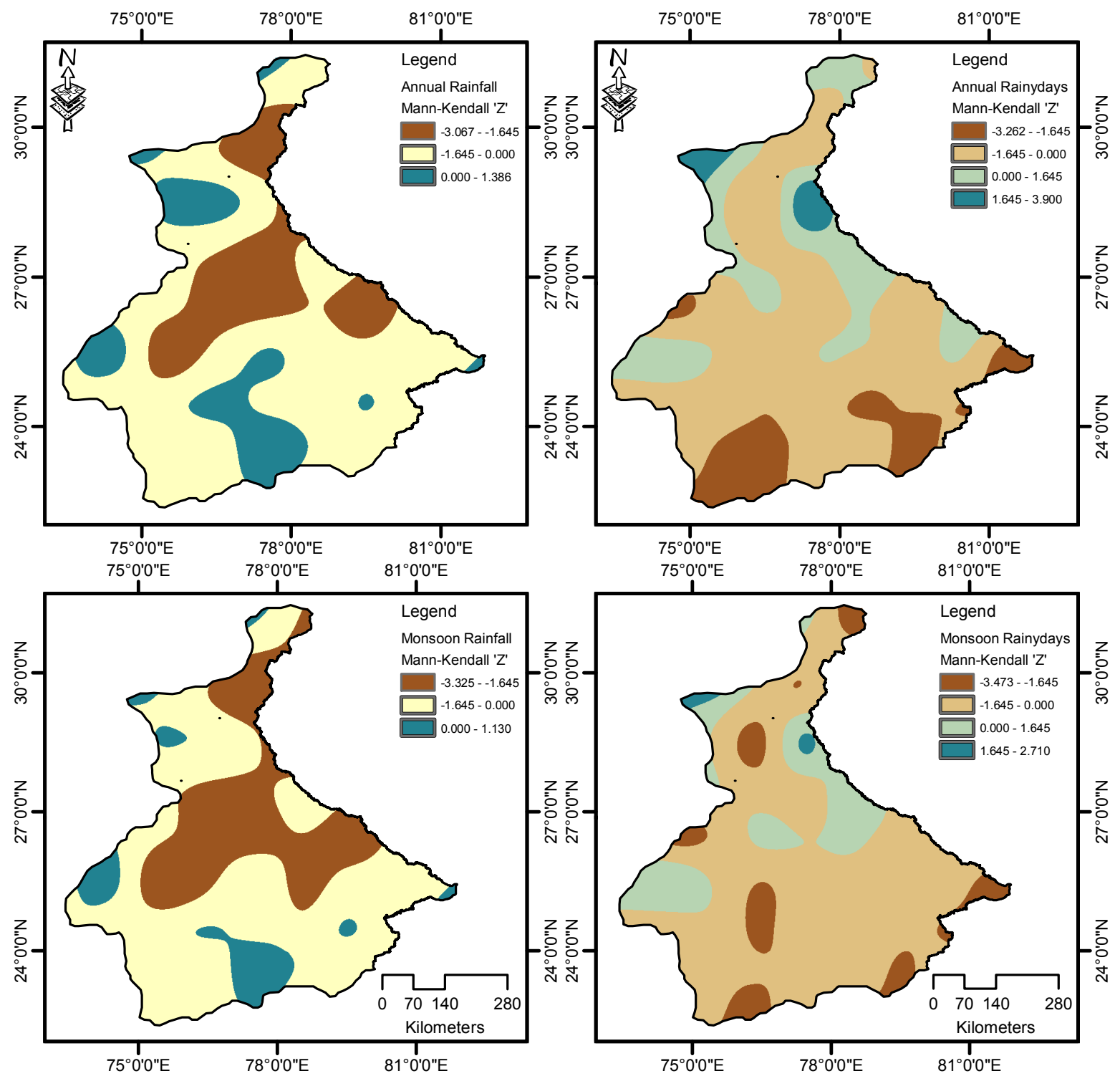
Fig. (6). contd....
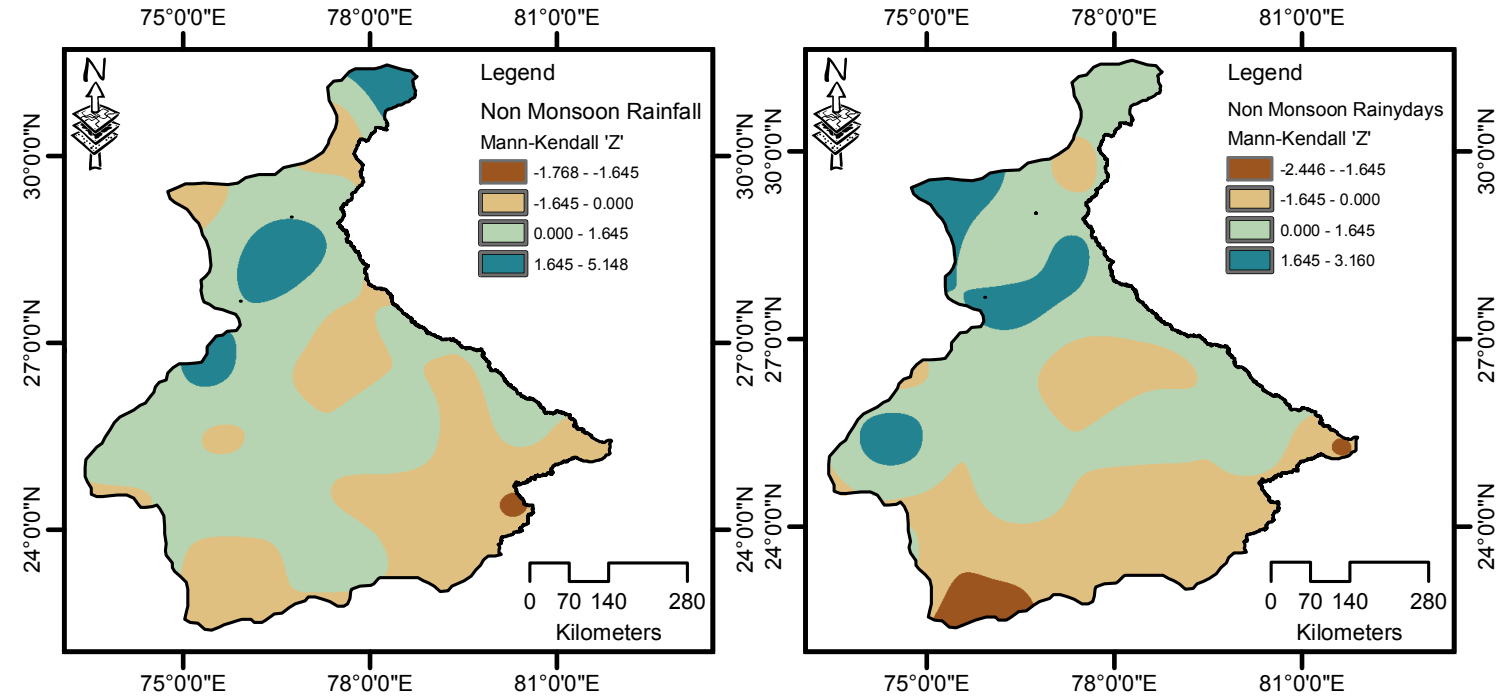

Fig. (6). Spatial distribution pattern of Mann-Kendall's Z-statistics of rainfall (annual, monsoon \& non-monsoon) and rainydays (annual, monsoon \& non-monsoon).
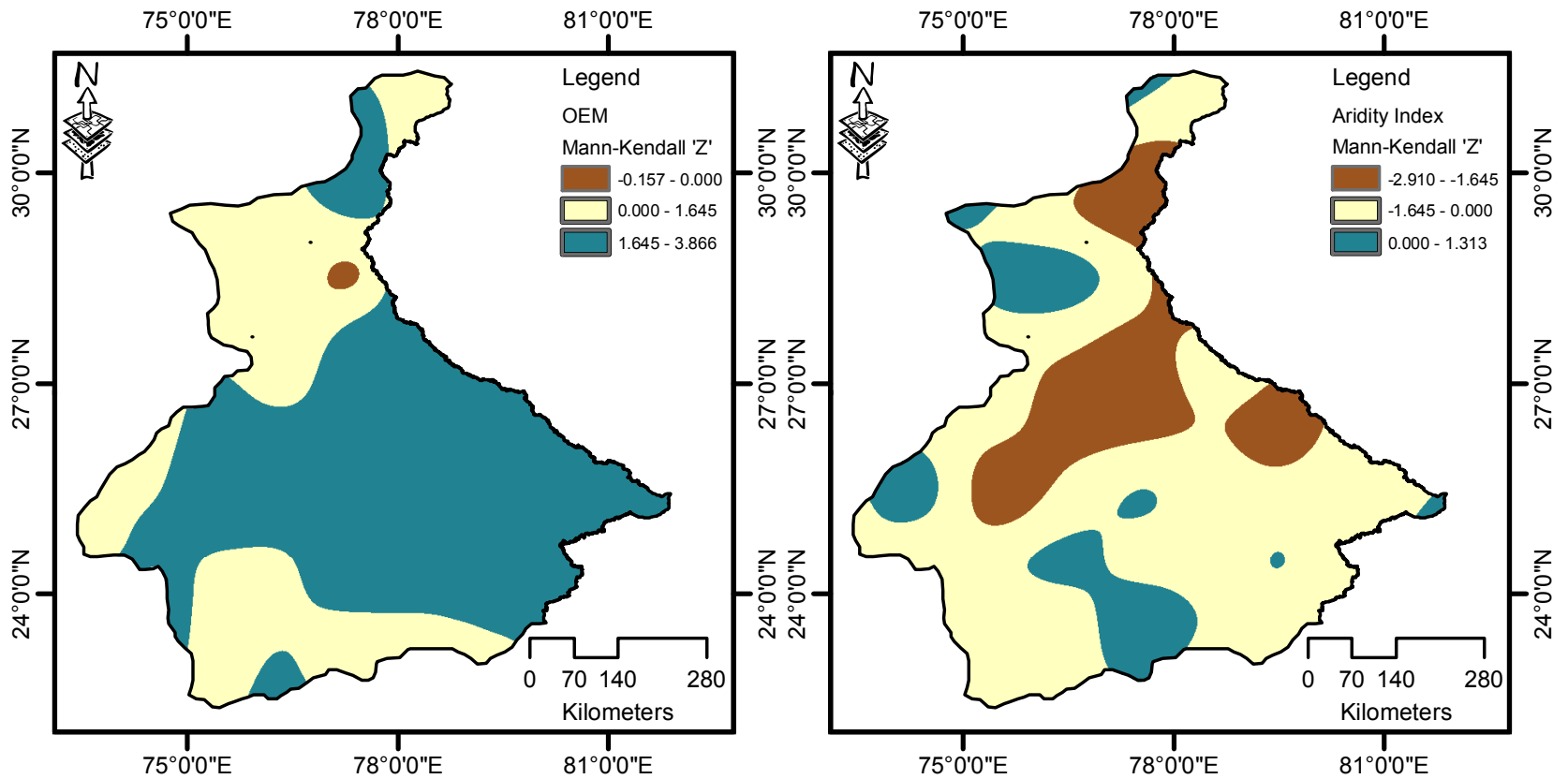

Fig. (7). Spatial distribution pattern of Mann-Kendall's Z-statistics of OEM and aridity index.

annual rainfall pattern and annual rainydays, and monsoon rainfall and monsoon rainydays were -0.832 and -0.362 , and -0.874 and -0.62 , respectively. On the other hand magnitude of non-monsoon rainfall has been insignificantly increased though few grid data show the significant rising trend in the north and north-west portion of the basin, which can be evident from the average Z-statistic of +0.209 and +0.258 for non-monsoon rainfall and rainydays was, respectively. Spatial distribution pattern of rainydays are more or less similar to the rainfall. Most of the area in the central to South-east and central to south experiences declination in the rainfall. Since, OEM is dependent on the rainfall pattern and potential evapotranspiration, and both the variable has shown a general falling trend in the basin. Therefore, increasing trend in the OEM was the resulting effect of the rainfall and evapotranspiration pattern. The overall mean Z-statistic for the OEM was +1.81. Similarly, aridity index is the ratio of annual rainfall and potential evapotranspiration. Falling trend observed in the aridity index is associated with the overall falling trend in the rainfall pattern of the Yamuna River basin (Table 7 and Fig. 6). The overall mean Z-statistic value for the in aridity index was -0.78 . Based on the trend analysis, it can be stated that the water resources potential of the Yamuna River basin is declining. 


\section{Periodicity}

Significance of the spectral estimates was evaluated at 90 and 95 percent confidence levels of the appropriate null continuum (red or white noise). The relationship between the correlogram and spectral estimates are shown in Fig. (8) for sample time series of annual rainfall of the Yamuna river basin. If a time series has persistence, the spectrum changes over all the wavelengths and the amplitude of the spectrum has a decreasing trend from long to short wavelengths (i.e. corresponding to increasing order of lags); and the spectrum is termed as 'red noise' (Fig. 8a). For the spectrum of a time series having persistence with necessary exponential relationship between $r_{1}, r_{2}$ and $r_{3}$ (i.e. Markov-type persistence), the appropriate null appropriate null hypothesis was assumed to be a Markov red noise continuum (Fig. 8b). A series characterized by an insignificant positive lag-1 SC or a series that has a significant positive lag-1 SC but not a simple Markov-type, and any series with negative lag-1 serial correlation coefficient was evaluated as a white noise continuum (Fig. 8c and 8d). From Fig. (8d), it may be stated that times series with negative lag-1 SC shows the high fre-
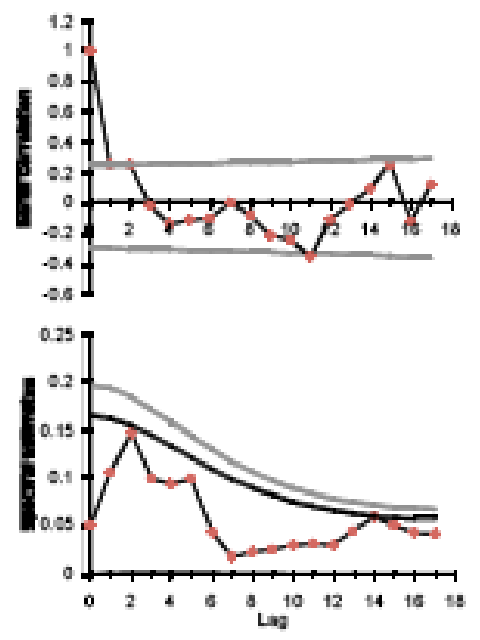

(2) Series with pervistence (rod noive)
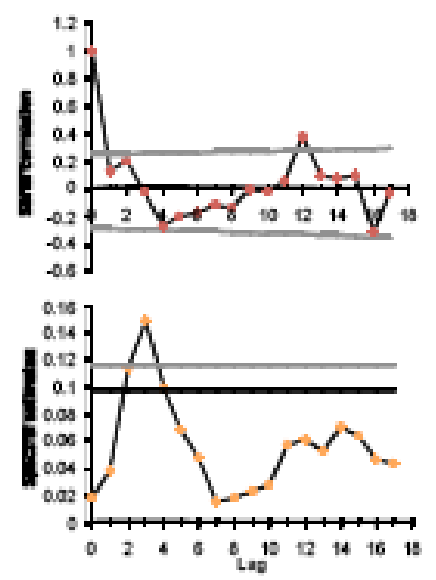

(c) Secios with insignificant pocititv lag-1 SC (whito
motso)

Fig. (8). Relation between correlogram and spectral estimates. quency variability (i.e. $L=14$, and $P=2 m / L=2.4$ years). For all the variables, power spectrum plots and the tables were prepared. However, for presentation, power spectrum plots of monsoon rainfall, OEM and AI are given (Figs. 9 through 11). To evaluate the power spectrum results, generally period values were computed using eq (26) (i.e. $P=$ $2 \mathrm{~m} / \mathrm{L}$ ) for all the time series. The computed values of period along with their significance level for monsoon rainfall, rainydays and OEM are given in Tables $\mathbf{1}$ through 3. Tables $\mathbf{1}$ - $\mathbf{3}$ also comprised of the serial correlation coefficients up to lag-3. Analysis revealed that the short-term period fluctuation of 2.0 to 4.9 years is dominant in the annual and monsoon rainfall, whereas, medium and long-term period of 5.0 to 34.0 years is dominant in case of non-monsoon rainfall. This short term periodic behavior (high frequency) of rainfall pattern in the Yamuna river basin should be kept in mind while preparing the water resources plan. In case of number of rainydays, the long-period is dominated over the shortperiodicity. Results of the power spectrum analysis of OEM and AI indicated that OEM and AI have dominating shortperiod fluctuations of 2.0 to 3.0 years, which leads to high probability of meteorological and agricultural drought and
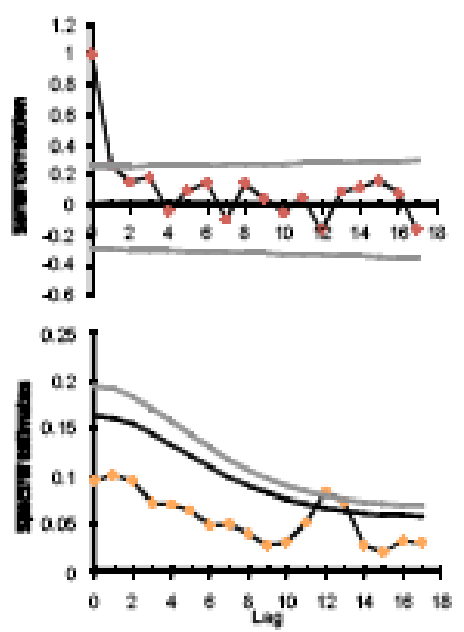

(b) Series with pervistence and vowing necessury expouential rolasoeship (Mrrisor red noino)

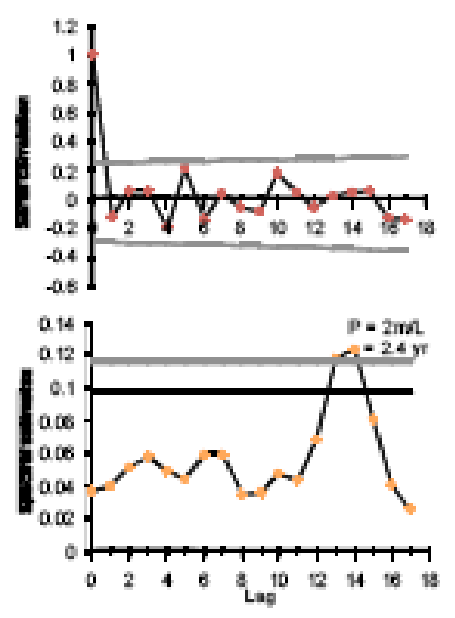

(d) Sarias with nagstivo log-1 SC (nhite noiso) 


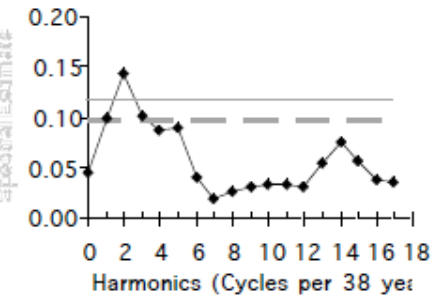

(10)

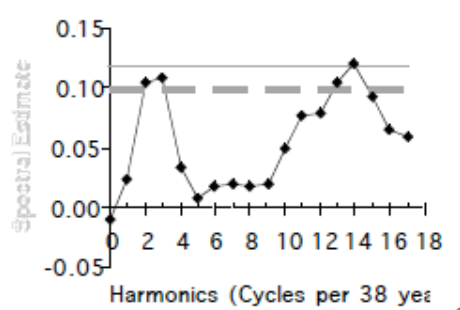

Harmonics (Cycles per 38 yes (21)

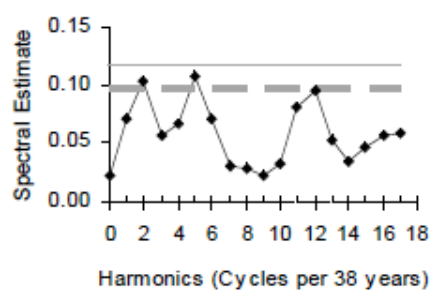

(27)

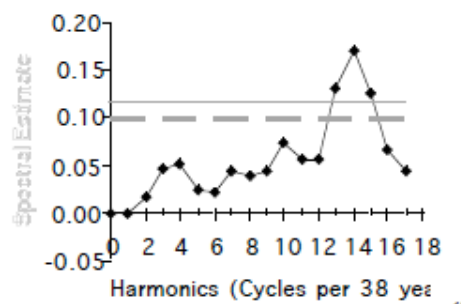

Harmonics (Cycles per 38 yes (33)

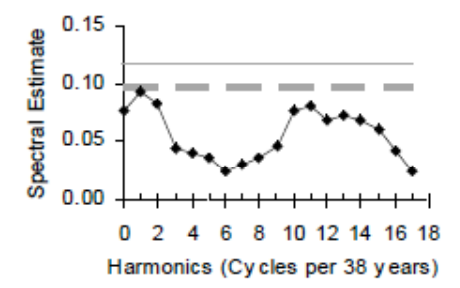

(42)

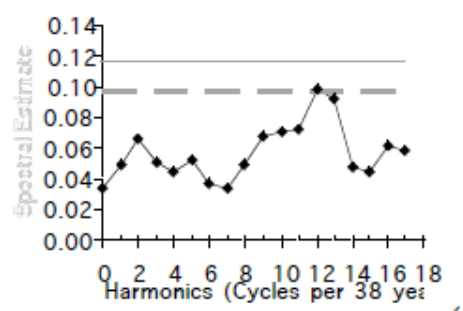

(49)

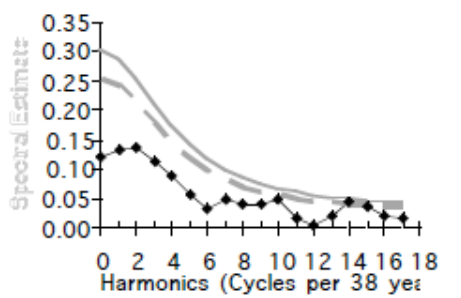

(61)
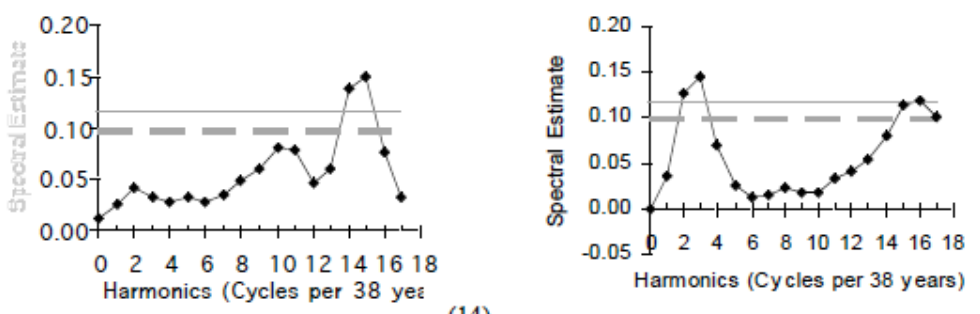

(14)
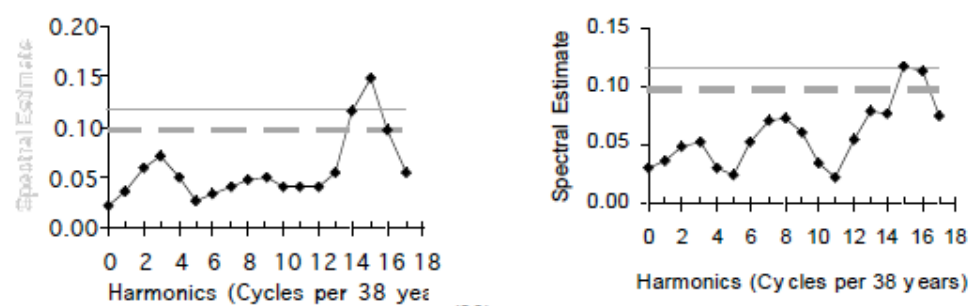

(23)
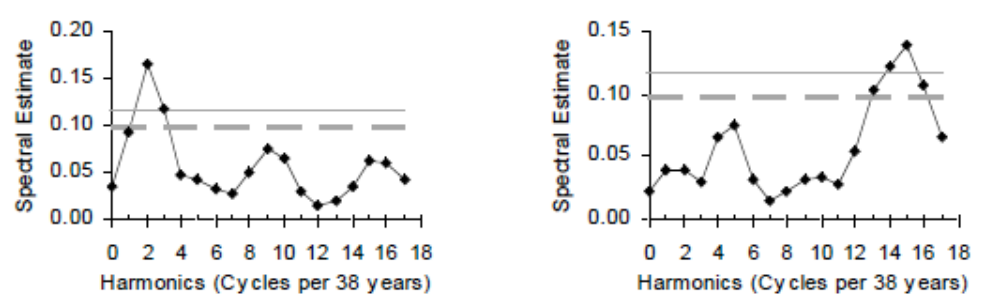

(29)
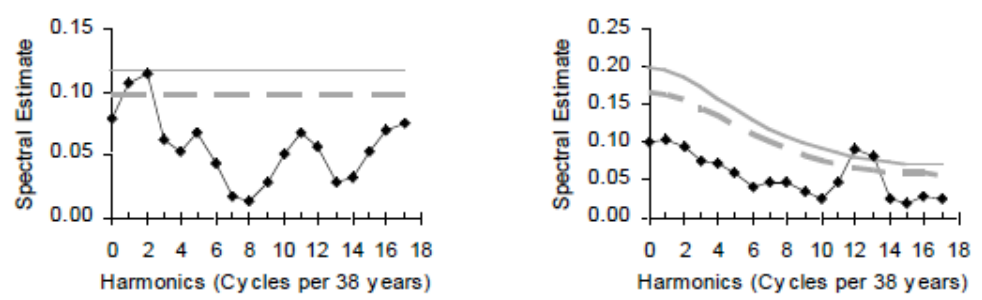

(31)

(40)

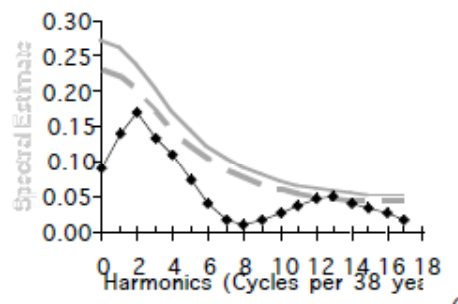

(45)
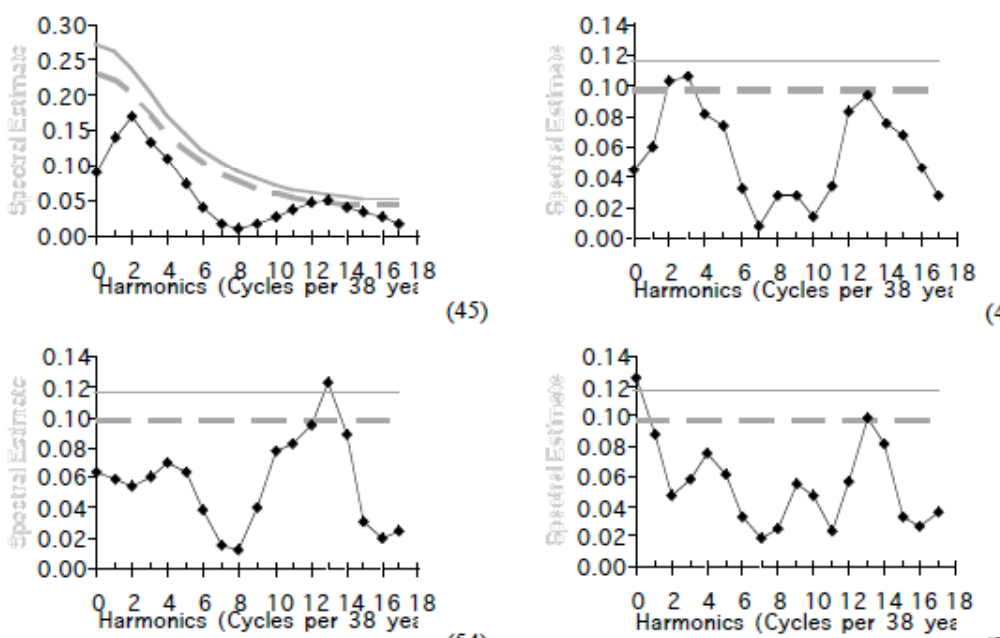

(54)

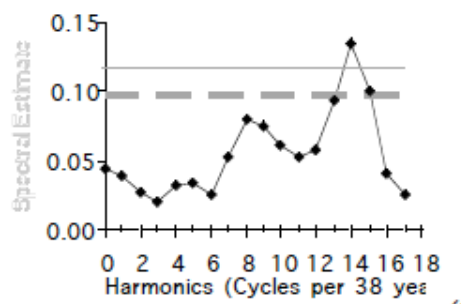

(63)
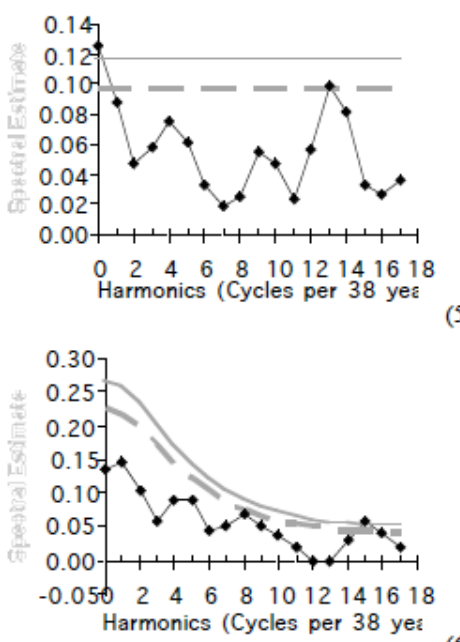

(64)

Fig. (9). Power spectrum plot for monsoon rainfall (_-_: $95 \%$ confidence limit; ----: $90 \%$ confidence limit). 


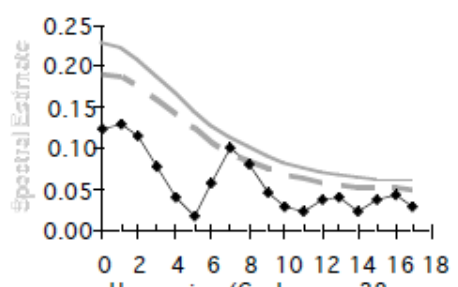

Harmonics (Cycles per 38 yez

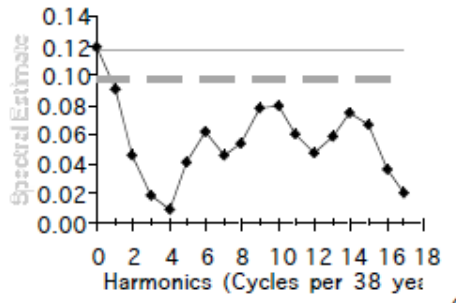

(21)

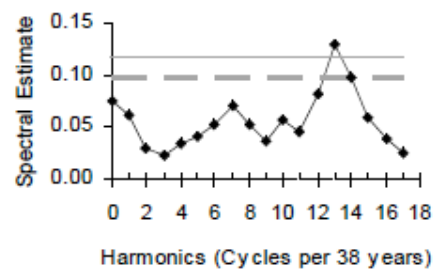

(27)
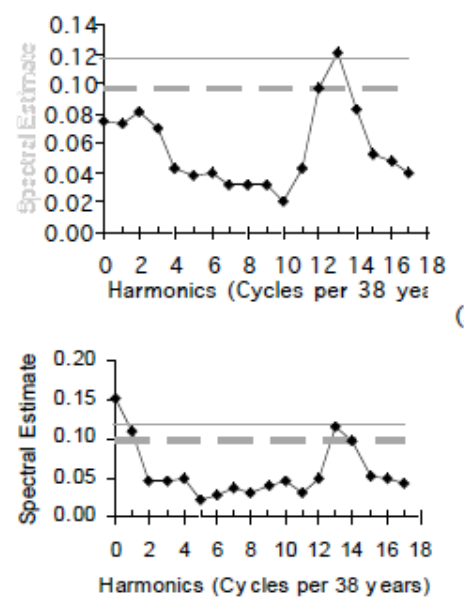

(42)

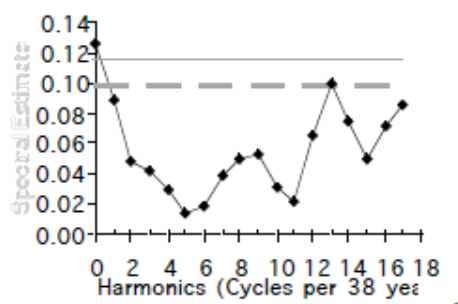

(49)

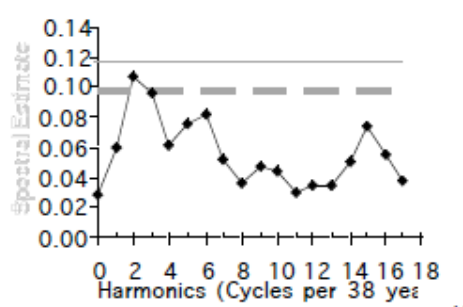

(61)

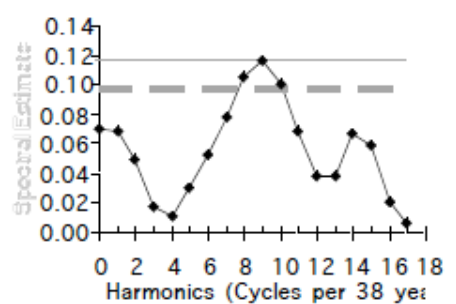

(14)
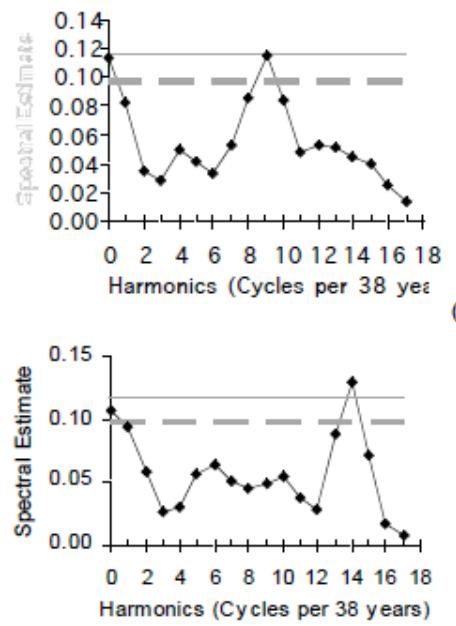

(23)

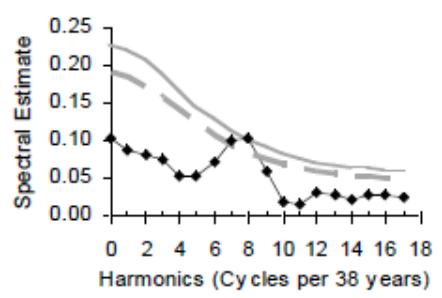

(19)

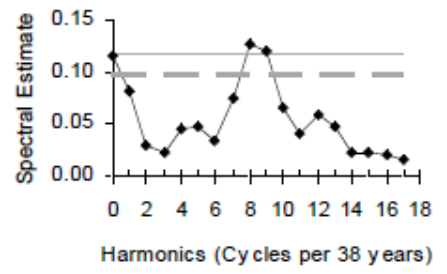

(25)

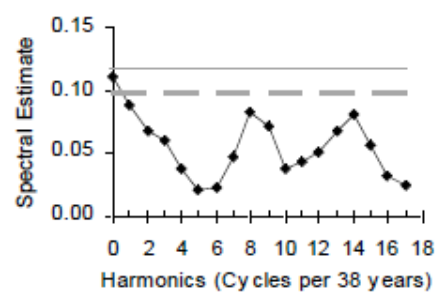

(29)
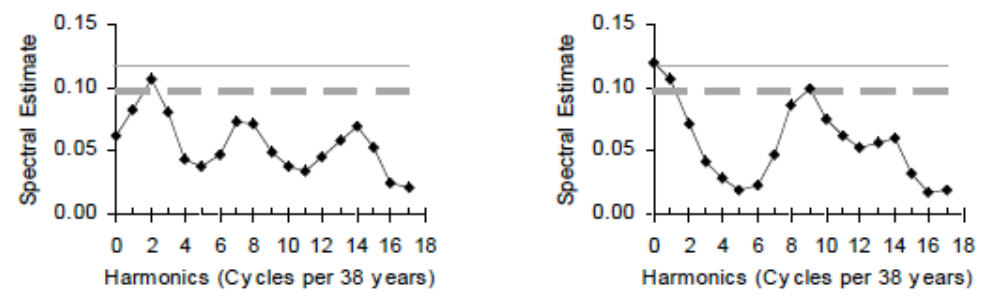

(38)
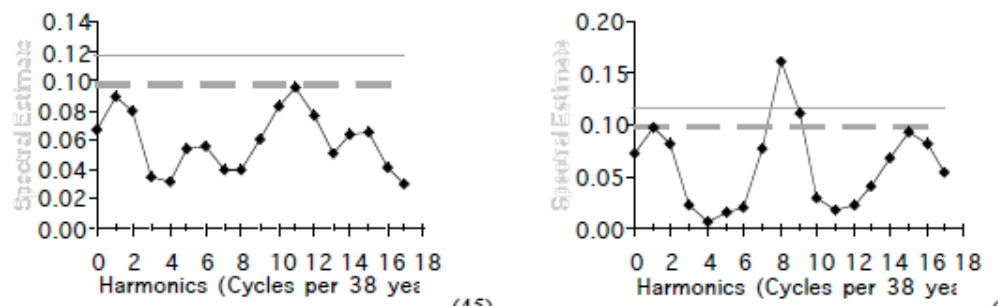

(45)
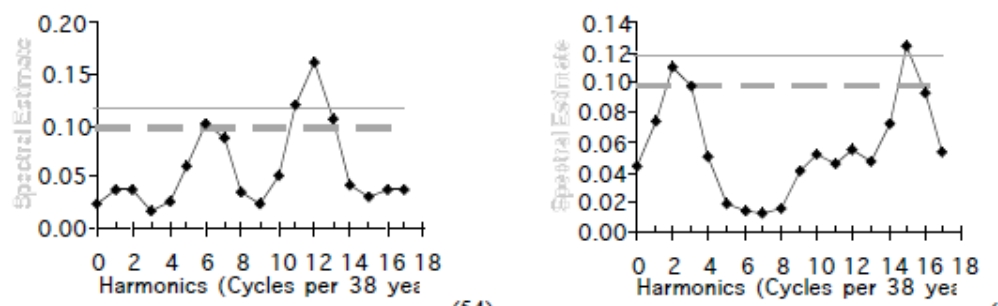

(54)
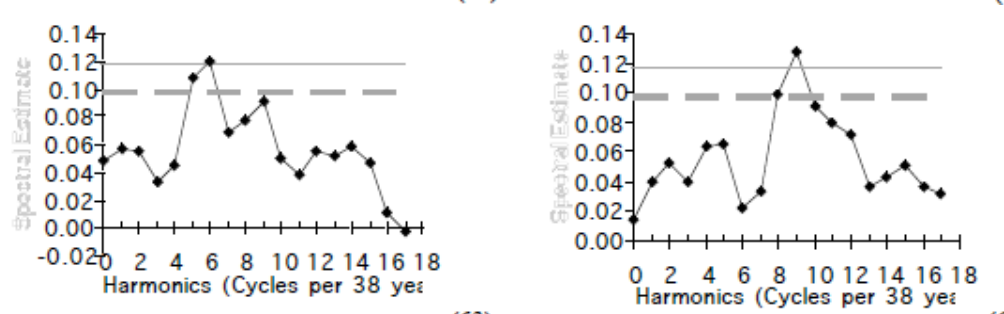

(63)
(31)

(40)

Fig. (10). Power spectrum plot for OEM (_- $95 \%$ confidence limit; ----: $90 \%$ confidence limit). 


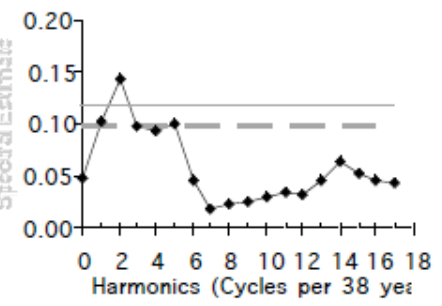

(10)

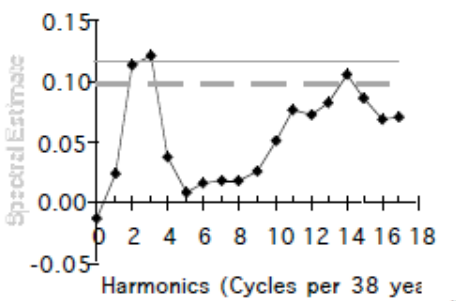

(21)

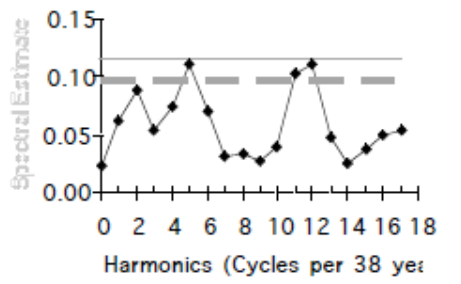

(27)

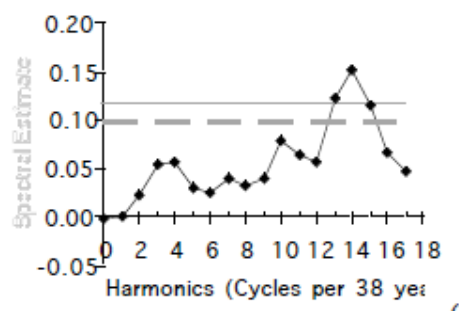

(33)

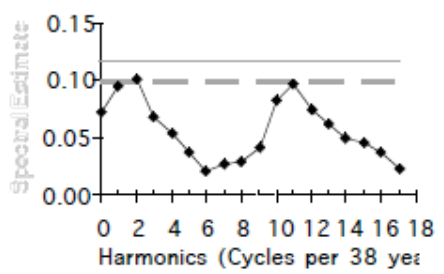

(42)
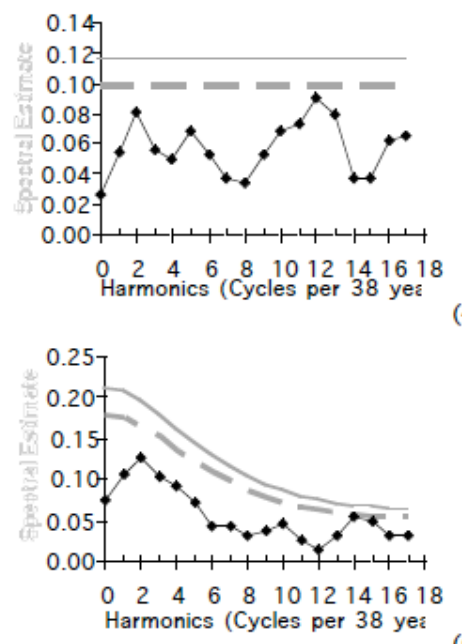

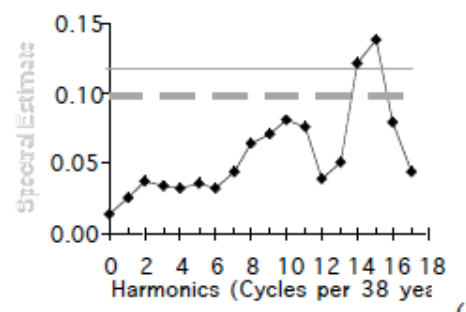

(14)

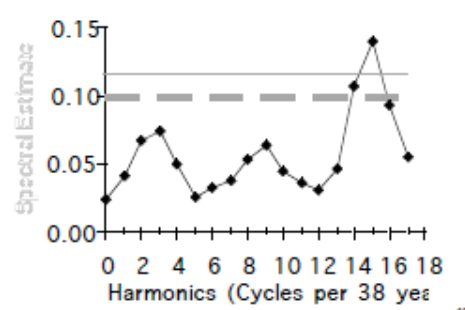

(23)

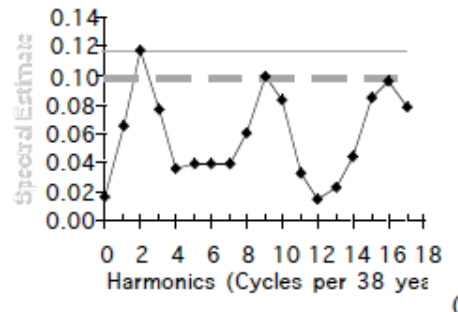

(29)

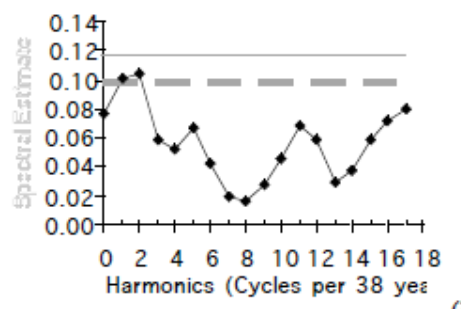

(38)

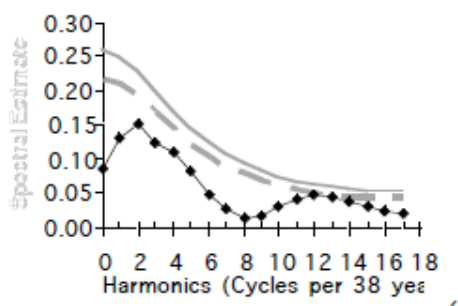

(45)

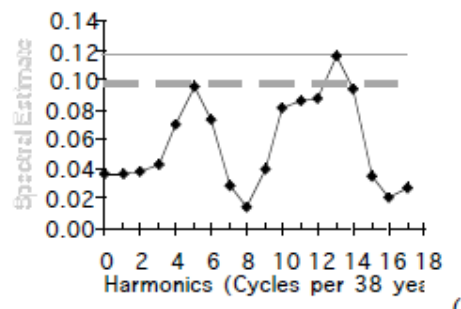

(54)

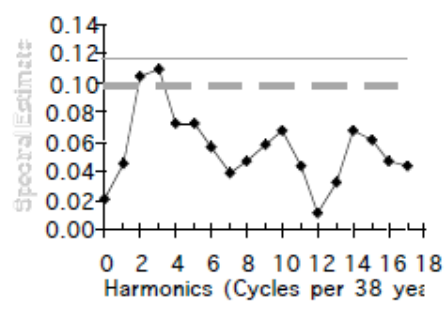

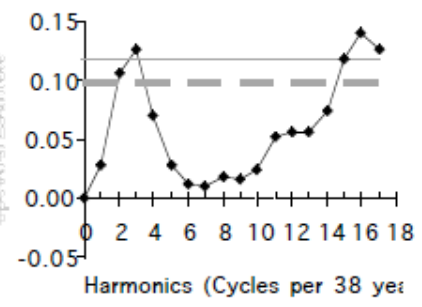
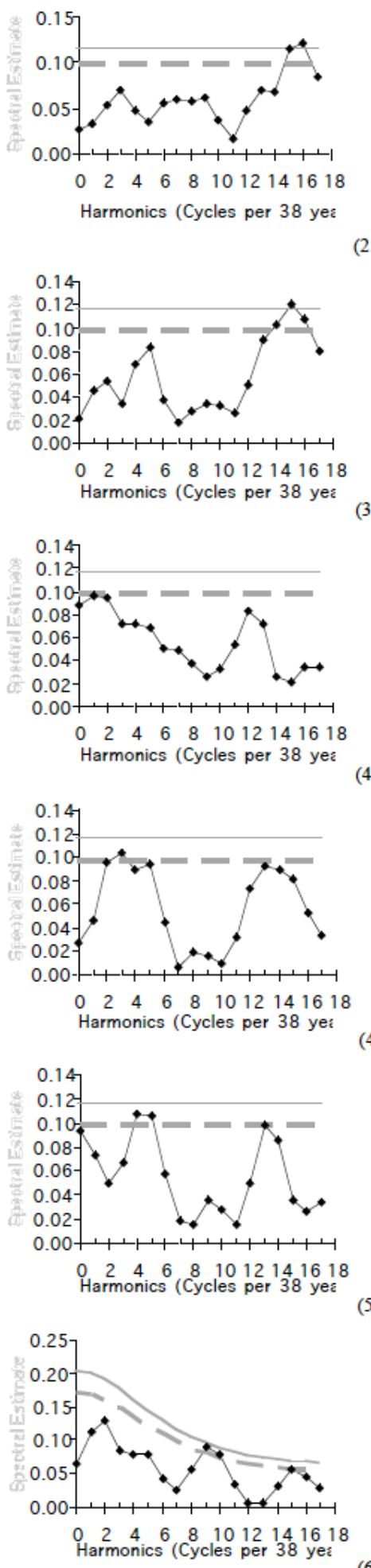

Fig. (11). Power spectrum plot for aridity index (AI) (___: $95 \%$ confidence limit; ----: $90 \%$ confidence limit). 
will frequently disturbs the planning of Kharif crops in the Yamuna river basin.

\section{CONCLUSIONS} drawn;

Based on the analysis, following conclusion can be

(i) There is a considerable difference in the monsoon and non-monsoon rainfall pattern in terms of persistence and periodicity.

(ii) Approximately 20 percent rainfall time series show the presence of persistence characterized by lag-1 serial correlation.

(iii) Presence of serial correlation in the time series significantly affects the Mann-Kendall's trend analysis.

(iv) Original Mann-Kendall test overestimate the presence of significant trend in the series than the modified Mann-Kendall and Mann-Kendall with Pre-whitening tests. Based on the overall trend results, the original Mann-Kendall test resulted approximately $37 \%$ more presence of significant trend than the modified MannKendall test.

(v) Overall falling trend was observed in the annual rainfall, monsoon rainfall, annual rainydays, monsoon rainydays, and AI. In sixty five grid locations, spatial mean of Mann-Kendall's Z-statistics for annual rainfall and monsoon rainfall were -0.832 and -0.874 , respectively. Regardless of few series having significant trend, most of the series have higher values of Zstatistic.

(vi) An increasing trend with overall mean Z-statistic of +1.81 was observed in OEM which shows the gradual delay in the onset of effective monsoon in the Yamuna river basin.

(vii) It may be remarked that the declining monsoon rainfall and number of monsoon rainydays along with the delay in the onset of effective monsoon (i.e. rising trend in OEM) will be the great concern while preparing the river basin management plan.

(viii) It was observed that high frequency fluctuations associated with short-period cycle is dominating over the basin for annual and monsoon rainfall, OEM and AI. However, for non-monsoon rainfall low frequency fluctuations were identified.

(ix) There was a good consistency between the lag-1 serial correlation and results of the power spectrum analysis. Positive lag-1 serial correlation coefficients gives low frequency fluctuations, whereas negative is an indicator for the high frequency (Fig. 8).

\section{REFERENCES}

[1] Reddy KR, Hodges HF. Climate change and global crop productivity. CAB International Publishing: UK 2000.

[2] Solomon S, Qin D, Manning M, et al. Ed. Climate change 2007: the physical science basis. In Contribution of Working Group I to the Fourth Assessment Report of the IPCC, Cambridge University Press: New York 2007.

[3] IPCC WG II. Climate Change 2007: Impacts, Adaptation and Vulnerability, Working Group II Contribution to the Intergovernmental Panel on Climate Change, Fourth Assessment Report, Summary for Policymakers 2007.
[4] Kothawale DR, Kumar R. On the recent changes in surface temperature trends over India. Geophys Res Lett 2005; 32, L18714

[5] Arora M, Goel NK, Singh P. Evaluation of temperature trends over India. Hydrol Sci J 2005; 50(1): 81-93.

[6] Kripalani RH, Oh JH, Kulkarni A, Sabade SS, Chaudhari HS South Asian summer monsoon precipitation variability: coupled climate model simulations and projections under IPCC AR4. Theor Appl Climatol 2007; 90(3-4): 133-59.

[7] Giakoumakis SG, Baloutsos G. Investigation of trend in hydrological time series of the Evinos River Basin. Hydrol Sci J 1997; 42(1): 81-8.

[8] Gan TY. Hydroclimatic trends and possible climatic warming in the Canadian Prairies. Water Resour Res 1998; 34(11): 3009-15.

[9] Ventura F, Pisa PR, Ardizzoni E. Temperature and precipitation trends in Bologna (Italy) from 1952 to 1999. Atmos Res 2002; 61: 203-14.

[10] Boyles RP, Raman S. Analysis of climate trends in North Carolina (1949-1998). Environ Int 2003; 29: 263-75.

[11] Mosmann V, Castro A, Fraile R, Dessens J, Sanchez JL. Detection of statistically significant trends in the Summer precipitation of Mainland Spain. Atmos Res 2004; 70: 43-53.

[12] Serrano A, Mateos VL, Garcia JA. Trend analysis of monthly precipitation over the Iberian Peninsula for the Period 1921-1995. Phys Chem Earth 1999; 24(1-2): 85-90.

[13] Xu ZX, Takeuchi K, Ishidaira H. Monotonic trend and step changes in Japanese precipitation. J Hydrol 2003; 279: 144-50.

[14] Dore MHI. Climate change and changes in global precipitation patterns: what do we know. Environ Int 2005; 31: 1167-81.

[15] Baines PG. The late 1960s Global Climate Shift and its influence on the Southern Hemisphere. Proc $8^{\text {th }}$ ICSHMO, INPE, Brazil, 2006; pp. 1477-82.

[16] Chase TN, Knaff JA, Pielke RA, Kalnay E. Changes in global Monsoon circulations since 1950. Nat Hazards 2003; 29: 229-54.

[17] Duan K, Yao T. Monsoon variability in the Himalayas under the condition of global warming. J Meteorol Soc Jpn 2003; 81(2): 2517.

[18] Pant GB. Long-term climate variability and change over monsoon Asia. J Ind Geophys Union 2003; 7(3): 125-34.

[19] Meher-Homji VM. Probable impact of deforestation on hydrological processes. Clim Change 1991; 19: 163-73.

[20] Hingane LS. Is a signature of Socio-economic impact written on the climate. Clim Change 1996; 32: 91-102.

[21] Kothyar UC, Singh VP, Aravamuthan V. An investigation of changes in rainfall and temperature regimes of the Ganga Basin in India. Water Resour Manage 1997; 11: 17-34.

[22] Chen TC, Hoon JH, Croix KJS, Takle ES. Suppressing impacts of the Amazonian deforestation by the Global Circulation Change. Bull Am Meteorol Soc 2001; 82(10): 2209-16.

[23] Lawton RO, Nair US, Pielke RA, Welch RM. Climatic impact of tropical lowland deforestation on nearby montane cloud forests. Science $2001 ; 294:$ 584-7.

[24] Nair US, Lawton RO, Welch RM, Pielke RA. Impact of land use on Costa Rican tropical montane cloud forests: Sensitivity of cumulus cloud field characteristics to lowland deforestation. J Geophys Res 2003; 108(D7): 4206-19.

[25] Ray DK, Nair US, Welch RM, et al. Effects of land use in Suthwest Australia: 1. Observations of cumulus cloudiness and energy fluxes. J Geophys Res 2003; 108(D14): 4414.

[26] Avissar R, Werth D. Global Hydroclimatological Teleconnections resulting from tropical deforestation. J Hydrometeorol 2005; 6: $134-45$.

[27] Gupta A, Thaplial, PK, Pal PK, Joshi PC. Impact of deforestation on Indian Monsoon - a GCM sensitivity study. J Ind Geophys Union 2005; 9(2): 97-104.

[28] Ray DK, Nair US, Lawton RO, Welch RM, Pielke RA. Impact of land use on Costa Rican tropical montane cloud forests: sensitivity of orographic cloud formation to deforestation in the plains. J Geophys Res 2006; 111: D02108

[29] Pielke RA. Influence of the spatial distribution of vegetation and soils on the prediction of cumulus convective rainfall. Rev Geophys 2001; 39(2): 151-77.

[30] Douglas EM, Niyogi D, Frolking S, et al. Changes in moisture and energy fluxes due to agricultural land use and irrigation in the Indian monsoon belt. Geophys Res Lett 2006; 33: L14403.

[31] Ramankutty N, Delire C, Snyder P. Feedbacks between agriculture and climate: an illustration of the potential unintended conse- 
quences of human land use activities. Glob Planet Change 2006; 54: 79-93.

[32] Pielke RA, Adegoke J, Beltr'an-Przekurat A, et al. An overview of regional Landuse and land-cover impacts on rainfall. Tellus B 2007; 59(3): 587-601.

[33] Ackerman AS, Toon OB, Stevens DE, et al. Reduction of tropical cloudiness by soot. Science 2000; 288: 1042-47.

[34] Ramanathan V, Crutzen PJ, Keihl JT, Rosenfeld D. Aerosols, climate and the hydrological cycle. Science 2001; 294: 2119-24.

[35] Ramanathan V, Chung C, Kim D, et al. Atmospheric brown clouds: impacts on South Asian climate and hydrological cycle. Proc Natl Acad Sci U S A 2005; 102(15): 5326-33.

[36] Sarkar S, Kafatos M. Interannual variability of vegetation over the Indian sub-continent and its relation to the different meteorological parameters. Remot Sens Environ 2004; 90: 268-80.

[37] Kripalani RH, Kulkarni A. Rainfall variability over southeast Asia-connections with Indian monsoon and ENSO extremes: New perspectives. Int J Climatol 1997; 17(11): 1155-68.

[38] Kripalani RH, Kulkarni A. Monsoon rainfall variations and teleconnections over South and East Asia. Int J Climatol 2001; 21(5): 603-16.

[39] Kripalani RH, Oh JH, Kulkarni A, Sabade SS, Chaudhari HS. South Asian summer monsoon precipitation variability: coupled climate model simulations and projections under IPCC AR4. Theor Appl Climatol 2007; 90(3-4): 133-59.

[40] Basistha A, Arya DS, Goel NK. Analysis of historical changes in rainfall in the Indian Himalayas. Int J Climatol 2009; 29: 555-72.

[41] Parthasarathy B, Dhar ON. A study of trends and periodicities in the seasonal and annual rainfall of India. Indian J Meteorol Hydrol Geophys 1976; 27(1): 23-8.

[42] Singh N, Sontakke NA, Singh HN, Pandey AK. Recent Trend in Spatiotemporal Variation of Rainfall over India - An investigation into Basin-scale Rainfall Fluctuation. IAHS-AISH Public 2005; 296: 273-82.

[43] Alvi SMA, Koteswaram P. Time series analyses of annual rainfall over India. Mausam 1985; 36(4): 479-90.

[44] Kumar RK, Pant GB, Parthasarathy B, Sontakke NA. Spatial and subseasonal patterns of the long-term trends of Indian summer monsoon rainfall. International J Climatol 1992; 12(3): 257-68.

[45] Lal B, Duggal YM, Ram P. Trends and periodicities of monsoon and annual rainfall of districts of Haryana State and Delhi. Mausam 1992; 43(2): 137-42.

[46] Rao GSP, Jaswal AK, Kumar MS. Effects of urbanization on meteorological parameters. Mausam 2004; 55(3): 429-40.

[47] Parthasarathy B, Dhar ON. Studies of trends and periodicities of rainfall over Madhya Pradesh. Proc Natl Acad Sci U S A 1976; 42(1A): 73-80.

[48] Senapati PC, Misra D. Distribution of rainfall in coastal region of Orissa. Ind J Power Riv Valley Dev 1988; 38(6): 193-8.

[49] Pant GB, Hingane LS. Climatic changes in and around the Rajasthan desert during the 20th century. J Climatol 1988; 8(4): 391401 .

[50] Zveryaev II, Aleksandrova MP. Differences in rainfall variability in the South and Southeast Asian summer monsoons. Int J Climatol 2004; 24(9): 1091-107.

[51] Singh N, Krishna Kumar K, Soman MK. Some features of the periods contributing specified percentages of rainfall to annual total in Kerala, India. Theoret Appl Climatol 1989; 39(3): 160-70.

[52] Singh N, Soman MK. Some aspects of hydroclimatic fluctuations in Kerala, India. Ind J Power Riv Valley Dev 1990; 40(5-6): $75-$ 84.

[53] Subbaramayya I, Naidu CV. Spatial variations and trends in the Indian monsoon rainfall. Int J Climatol 1992; 12(6): 597-609.

[54] Singh P, Kumar V, Thomas T, Arora M. Changes in rainfall and relative humidity in river basins in northwest and central India. Hydrol Process 2007; DOI: 10.1002/hyp.6871.

[55] Kothyari UC, Singh VP. Rainfall and temperature trends in India. Hydrol Process 1996; 10(3): 357-72.

[56] Singh N, Sontakke NA. On climatic fluctuations and environmental changes of the Indo-Gangetic Plains, India. Clim Change 2002; 52(3): 287-313.

[57] IINC. India's Initial National Communication to the United Nations Framework Convention on Climate Change, Ministry of Environment \& Forests, Govt. of India 2004.

[58] Chase TN, Knaff JA, Pielke RA, Kalnay E. Changes in global Monsoon circulations since 1950. Nat Hazards 2003; 29: 229-54.
[59] Baines PG. The late 1960s Global Climate Shift and its influence on the Southern Hemisphere. In Proc $8^{\text {th }}$ ICSHMO, INPE, Brazil 2006, pp. 1477-82.

[60] Jhajharia D, Shrivastava SK, Sarkar D, Sarkar S. Temporal characteristics of pan evaporation trends under the humid conditions of northeast India. Agric Forest Meteorol 2008; (doi: 10.1016/j/agrformet.2008.10.024).

[61] Bandyopadhyay A, Bhadra A, Raghuwanshi NS, Singh R. Temporal Trends in Estimates of Reference Evapotranspiration over India. J Hydrol Eng 2009; 14 (5): 508-15.

[62] WMO. Climatic change, World Meteorological Organization, Geneva 1966; WMO Technical note 79.

[63] Matalas NC. Time series analysis. Water Resour Res 1967; 3: 817-29.

[64] Rodhe H, Virji H. Trends and periodicities in East African rainfall data. Mon Weather Rev 1976; 104: 307-15.

[65] Granger OE. Secular fluctuations of seasonal precipitation in lowland California. Mon Weather Rev 1977; 105: 386-97.

[66] Ogallo L. Rainfall variability in Africa. Mon Weather Rev 1979; 107: 1133-39.

[67] Anyadike RNC. Seasonal and annual rainfall variations over Nigeria. Int J Climatol 1993; 13: 567-80

[68] Drosdowsky W. An analysis of Australian seasonal rainfall anomalies: 1950-1987. II: Temporal variability and teleconnection patterns. Int J Climatol 1993; 13: 111-49.

[69] Nicholson, S.E., Palao, I.M. A re-evaluation of rainfall vari- ability in the Sahel. Part I. Characteristics of rainfall fluctuations. Int J Climatol 1993; 13: 371-89.

[70] Türkes M. Influence of geopotential heights, cyclone frequency and Southern Oscillation on rainfall variations in Turkey. Int $\mathbf{J}$ Climatol 1998; 18: 649-80.

[71] Türkes M. Vulnerability of Turkey to desertification with respect to precipitation and aridity conditions. Trans J Eng Environ Sci 1999; 23: 363-80.

[72] Türkes M, Sümer UM, Kiliç G. Persistence and periodicity in the precipitation series of Turkey and associations with $500 \mathrm{hPa}$ geopotential heights. Clim Res 2002; 21: 59-81.

[73] Yevjevich V. Stochastic Processes in Hydrology. Water Resources Publications, Fort Collins: CO 1971.

[74] Mann HB. Non-parametric tests against trend. Economet 1945; 13: 245-59.

[75] Kendall MG. Rank Correlation Methods, Charles Griffin: London 1955.

[76] Hirsch RM, Slack JR, Smith RA. Techniques of trend analysis for monthly water quality data. Water Resour Res 1982; 18(1): 10721.

[77] Hirsch RM, Slack JR. A nonparametric trend test for seasonal data with serial dependence. Water Resour Res 1984; 20(6): 72732.

[78] Lettenmaier DP, Wood EF, Wallis JR. Hydro-climatological trends in the continental United States 1948-1988. J Clim 1994; 7(4): 586-607.

[79] Lins HF, Slack JR. Streamflow trends in the United States. Geophys Res Lett 1999; 26(2): 227-30.

[80] Douglas EM, Vogel RM, Kroll CN. Trends in floods and low flows in the United states: Impact of spatial correlation. J Hydrol 2000; 240(1-2): 90-105.

[81] Burn DH, Elnur MA. Detection of hydrologic trends and variability. J Hydrol 2002; 255: 107-22.

[82] Yue S, Pilon P, Cavadias G. Power of the Mann-Kendall and Spearman's rho test for detecting monotonic trends in hydrological series. J Hydrol 2002; 259: 254-71.

[83] Yue S, Pilon P. A comparison of the power of the $t$-test, MannKendall and bootstrap tests for trend detection. Hydrol Sci J 2004; 49(1): 21-37.

[84] Burn DH, Cunderlink JM, Pietroniro A. Hydrological trends and variability in the Liard river basin. Hydrol Sci J 2004; 49(1): 5367.

[85] Zhang, Q, Jiang, T, Gemmer, M, Becker, S. Precipitation, temperature and runoff analysis from 195-2002 in the Yangtze basin, China. Hydrol Sci J 2005; 50(1): 65-80.

[86] Aziz OIA, Burn DH. Trends and variability in the hydrological regime of the Mackenzie River Basin. J Hydrol 2006; 319(1-4): 282-94.

[87] Chen H, Guo S, Xu CY, Singh VP. Historical temporal trends of hydro-climatic variables and runoff response to climate variability 
and their relevance in water resource management in the Hanjiang basin. J Hydrol 2007; 344: 171-84.

[88] Cox DR, Stuart A. Some quick tests for trend in location and dispersion. Biometrika 1955; (42): 80-95.

[89] Khaliq MN, Ouarda TBMJ, Gachon P, Sushma L, St-Hilaire A. Identification of hydrological trends in the presence of serial and cross correlations: A review of selected methods and their application to annual flow regimes of Canadian rivers. J Hydrol 2009; 368: $117-30$

[90] Wiener N. Generalized harmonic analysis. Acta Math 1930; 55: $117-258$.

[91] Wiener N. Extrapolation, interpolation, and smoothing of stationary time series. MIT Press, Cambridge: Massachusetts 1949.

[92] Tukey JW. The sampling theory of power spectrum estimates. In: Symposium on applications of autocorrelation analysis to physical problems. US Office of Naval Research, NAVEXOS-P-735: 4767, Washington; DC 1950.

[93] Blackman RB, Tukey JW. The measurement of power spectra. Dover Publications: New York 1958.

[94] Jenkins GM, Watts DG. Spectral analysis and its applications. Holden-Day: San Francisco 1968.

[95] Julian PR. Variance spectrum analysis. Water Resour Res 1967; 3 : 831-45.

[96] Ashokraj PC. Onset of effective monsoon and critical dry spell-A computer based forecasting technique. Indian Agricultural Research Institute, ICAR, New Delhi, Bul no 11: India 1979.

[97] UNEP. World Atlas of Desertification, the United Nations Environment Programme (UNEP): London 1993.

[98] Thornthwaite CW. An approach toward a rational classification of climate. Geogr Rev 1948; 38: 55-94.

(C) Rai et al.; Licensee Bentham Open.

This is an open access article licensed under the terms of the Creative Commons Attribution Non-Commercial License (http://creativecommons.org/licenses/by-nc/3.0/) which permits unrestricted, non-commercial use, distribution and reproduction in any medium, provided the work is properly cited. 